\title{
Emerging Cities as Independent Engines of Growth: The Case of Buenos Aires
}

\author{
Ricardo Hausmann, Douglas Barrios, Daniela Muhaj, Sehar Noor, Carolina \\ Pan, Miguel Angel Santos, Jorge Tapia, Bruno Zuccolo
}

CID Faculty Working Paper No. 385

October 2020

(C) Copyright 2020 Hausmann, Ricardo; Barrios, Douglas; Muhaj, Daniela; Noor, Sehar; Pan, Carolina; Santos, Miguel Angel; Tapia, Jorge; Zuccolo, Bruno; and the President and Fellows of Harvard College
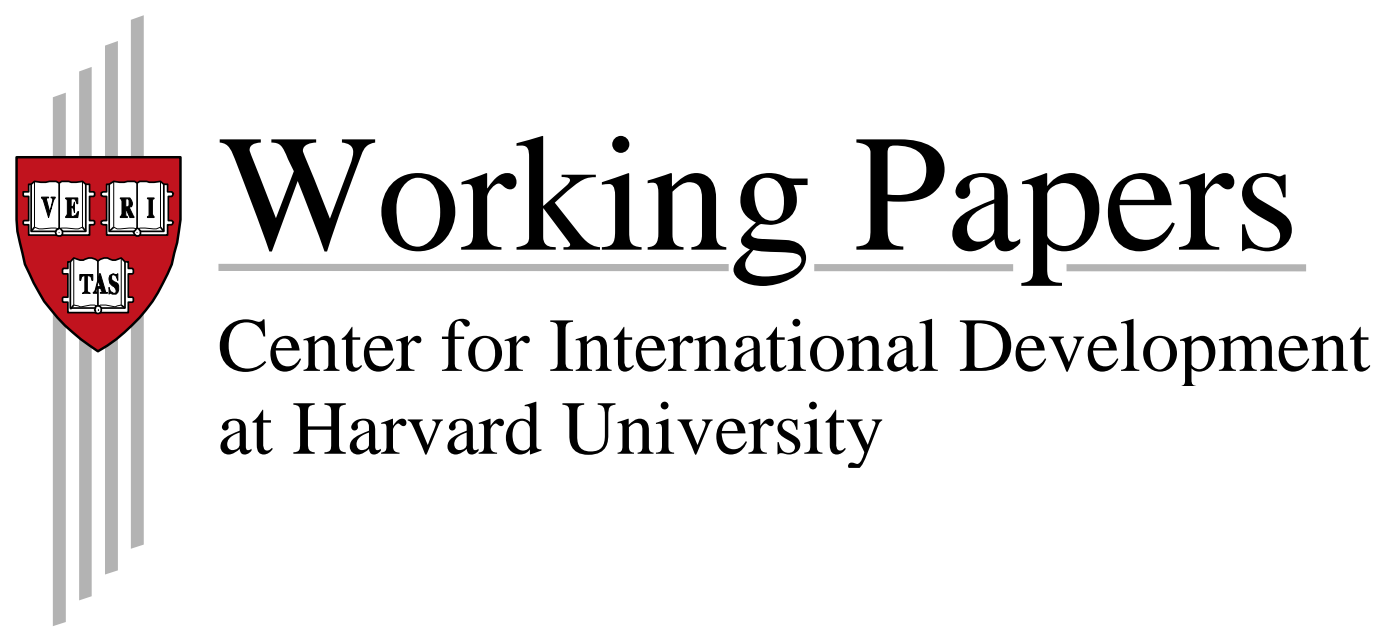


\title{
Emerging Cities as Independent Engines of Growth: The Case of Buenos Aires
}

\author{
Ricardo Hausmann, Douglas Barrios, Daniela Muhaj, Sehar Noor, Carolina Pan, Miguel Angel
} Santos, Jorge Tapia, and Bruno Zuccolo

October 2020 


\section{Table of Contents}

I. Executive Summary 4

II. Buenos Aires' Growth Performance 9

III. Most Binding Constraints to Economic Growth 14

1. Tax Rates 14

2. Employment Regulations 17

3. Potential Future Constraints to Growth 21

i. Access to Financing 21

ii. Regulatory Foreseeability 22

IV. Economic Complexity Analysis and Opportunities for Export Diversification 22

1. Productive Structure and Complexity Indicators 23

2. Diversification Opportunities 26

3. Prioritization of Productive Diversification Efforts 27

i. Viability Factors: $\quad 28$

ii. Attractiveness Factors: 29

V. Conclusions and Policy Recommendations 32

1. Inputs for Designing Policies Aimed at Easing Constraints 33

2. Policies Aimed at Tackling Constraints 35

3. Productivity Task Forces 39

4. Investment Promotion 41

VI. References 43

ANNEX I: Attachments $\quad 44$

1. Distribution of Exports in Sectors in which Buenos Aires is Intensive (2016) 44

2. Thematic Areas, Thematic Subareas, and Industries 45

3. Description of Thematic Areas and Subareas 48

4. Methodology for Estimating Missing Occupations and Inputs 51

5. Performance in Viability and Attractiveness Factors (Example) 53

ANNEX II: Methodological Framework

1. Growth Diagnostic 55

2. Economic Complexity Analysis $\quad 57$ 


\section{Table of Figures}

Figure 1: Trends in per capita GRDP (2004-17, 2004=100), Buenos Aires and the rest of the Argentina

Figure 2: Breakdown of competitiveness effect / place-specific effect by sector (2004-17), Buenos

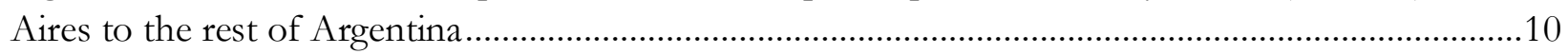

Figure 3: (a) Trend in per capita GDP (2004-18, 2004=100), Buenos Aires and regional peers; (b) Trend in per capita GDP $(2011-18,2011=100)$, Buenos Aires and international peers .....................11

Figure 4: Exporting and disconnecting capacity, Buenos Aires and peers ........................................12

Figure 5: Exports per worker in sectors in which Buenos Aires is intensive (2016), Buenos Aires and peers

Figure 6: Tax rates as percentage of profits and identification of tax rates as the main obstacle (2017), Buenos Aires and world capitals

Figure 7: Size (employment) ratio between exporting and non-exporting companies (2015), Buenos Aires and international peers....

Figure 8: Advance notice and severance pay associated with layoffs (2017), Buenos Aires and world capitals.

Figure 9: Perception of flexibility in hiring/dismissals and perception of effects of employment taxes on employment incentive (2017), all countries

Figure 10: Percentage of companies having more than 100 employees by economic sector (2015), Buenos Aires and average among relevant peers

Figure 11: Proportion of activities in which Buenos Aires shows a Revealed Comparative Advantage according to the structural prevalence of large companies (2015), Buenos Aires

Figure 12: Industry Space, Buenos Aires.

Figure 13: Economic Complexity Index and Per Capita GDP, Buenos Aires and international peers

Figure 14: Prioritization of activities by thematic area and thematic subarea, all diversification opportunities. .31

Figure 15: Productive development policies for Buenos Aires .33

Figure 16: Property taxes: (a) rates, (b) collection (\% of income) .34

Figure 17: Share of areas and subareas in Phases 0 and 1 .37

Figure 18: Segments with more than 10\% of opportunities in Phases 0 and 1 .38 
Figure 19: Description of the implementation process of productive task forces.

Figure 20: Distribution of exports in sectors in which Buenos Aires is intensive (2016), Buenos Aires

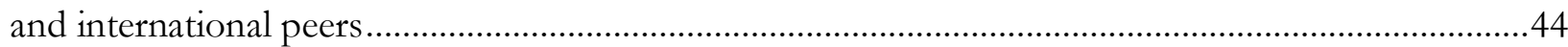

Figure 21: Performance in viability factors, TV production and other postproduction services .........53

Figure 22: Performance in attractiveness factors, TV production and other postproduction services 


\section{Executive Summary}

Is it possible for a state or a city to decouple its growth trajectory from that of its country? The answer to this question is not binary. Rather, it comes expressed in degrees that vary across places, and ultimately depends on the interaction of the factors that a sub-national unit shares with its country, and those that make it unique. On the one hand, sub-national units are generally subject to a series of country-level features that influence investment and growth patterns: the national legal framework and system of political representation, macroeconomic factors such as exchange rate regime, sovereign risk and interest rates; trade policy, labor regulations, and - in most cases - even the quality and history of institutions. On the other hand, sub-national units can exhibit stark contrasts with rest of the country in other relevant factors, like the variety and depth of know-how agglomeration they possess, the quality of diversity of its public goods, and its capacity to attract both capital and talent from outside its boundaries. Thus, the degree to which a city or state's growth trajectory can diverge from its country's will likely be determined by which of these set of factors is more predominant, and how these factors interact with each other.

Ex-ante, given the sheer number of factors that sub-national units share with the countries that they are a part of - and are thus conditioned by -it is difficult to imagine how a city's growth trajectory can differ significantly from the national trend, if at all. However, when analyzing within-country income gaps, we find that these not only tends to be large but are reproduced in a fractal nature as we move into smaller geographical units. In Mexico, for example, by 2015, the richest state (Nuevo Leon) was 6.1 times richer than the poorest state (Chiapas); within Chiapas, the richest municipality (Tuxtla Gutierrez) was 8.5 times richer than the poorest one (Mitontic). In light of these levels of disparity within countries, one might wonder if its sensible to think about growth strategies exclusively from a national perspective.

So, what does it take for a sub-national unit to become an autonomous engine of growth? This issue is particularly relevant to large cities, as they tend to display larger and more complex know-how agglomerations and may have access to a broader set of policy tools. To approximate an answer to this question, specific to the case of Buenos Aires, Harvard's Growth Lab engaged in a research project from December 2018 to June 2019, partnering with the Center for Evidence-based Evaluation of Policies (CEPE) of Universidad Torcuato di Tella, and the Development Unit of the Secretary of Finance of the City of Buenos Aires. Together, we have developed research agenda that seeks to provide inputs for a policy plan aimed at decoupling Buenos Aires's growth trajectory from the rest of Argentina's. This report summarizes the main findings of this research.

Once known as one of the richest cities in the world, Buenos Aires remains a cosmopolitan metropolis that ranks among the Latin American capitals with the highest incomes per capita. It is also a city embedded into the economic and political roller coaster that is Argentina. One would be hard-pressed to think of a better case study in growth-trajectory decoupling than Buenos Aires. 
Over the past 15 years, Buenos Aires has displayed a growth trajectory that diverged from that of the country at large. During the commodity boom (2004-2011), the city grew at a per capita rate much higher than Argentina (6.2\% vs. 3.6\%), and during the growth deceleration that followed (2011-2017), it contracted far less $(-0.1 \%$ vs. $-1.1 \%)$. The main driver of these differences in performance was not an industry composition effect, but rather a place-specific effect. In other words, it is not that Buenos Aires was more intensive in industries that grew faster at a national level, but rather that industries in Buenos Aires performed better than at a national level.

Even though, Buenos Aires's performance was favorable relative to Argentina's it what far less impressive when compared to international peers. Within Latin America, it grew faster than most peer cities during the expansion (2004-2011), but stagnated afterwards (2011-2018) in such a way that, in the aggregate, it only grew more than Rio de Janeiro and Sao Paulo. The plausible explanation of convergence (richer places tend to growth at a slower pace) can likely be ruled out, since Buenos Aires's displayed the worst economic performance of a group of twelve international peers with higher levels of income.

The unfavorable economic performance of Buenos Aires vis-à-vis international peers may be linked to the comparably lower ability to diverge from the national trends. Within our peer groups of cities, and during the period of analysis, the degree at which Buenos Aires's performance decoupled from the national trend was the second lowest; almost all other cities within Latin America and other parts of the world were able to distance their growth trajectory further from their corresponding countries. We provide suggestive evidence indicating that the lower degree of decoupling is associated with the low productivity of the export sector in Buenos Aires, which makes the economy of the city more reliant on domestic demand, and thereby more vulnerable to domestic macroeconomic volatility.

It follows, then, that strategies aimed at turning the city into an autonomous engine of growth should focus on increasing the competitiveness of its exports. Those efforts shall be aimed at identifying industries with higher export potential already present in Buenos Aires (intensive margin), and on attracting productive know-how (i.e.: foreign direct investment, talent, etc.) related to new tradable goods and services (extensive margin). In order to identify the most attractive opportunities, we have deployed the Economic Complexity framework (Hidalgo and Hausmann, 2009). The central tenet is that places reveal their stock of productive know-how through the goods and services they are able to produce competitively, and that future diversification tends to occur along products that require similar know-how and capacities than those already in place. Based on that notion, it is possible to define a place-specific roadmap for export diversification, tailored to the variety and depth of the location's current know-how agglomeration.

We have approximated the know-how agglomeration of Buenos Aires and that of comparable cities using the Dun \& Bradstreet dataset, relying on metrics derived from relative intensity of employment at the industry level. This exercise revealed three important insights. First, the know-how 
agglomeration of Buenos Aires - as represented by its Economic Complexity Index (ECI) - is lower than in most comparable cities. Second, Buenos Aires's income per capita level is higher than what one would expect given its ECI, a feature that, in the absence of policy interventions, tends to be associated with future decelerations or stagnations in growth. Thirdly, in spite of its lower ECI, Buenos Aires has significant opportunities to expand its exports of goods and services to more complex industries that rely on productive capacities that are similar to those already in place. These opportunities pave the way for a more proactive scenario, whereby the city adopts policies aimed at increasing the complexity and size of its exports as a means of decoupling its economy from Argentina's. Our initial analysis based on complexity metrics has identified 39 products and services (out of the 213 codified industries that are already present in the city) on the intensive margin, and 70 more on the extensive margin (out of the total 845 that are not present) that have significant potential to underpin this process.

What has prevented these latent opportunities from realizing? We have gathered extensive quantitative and qualitative evidence indicating that tax rates and labor regulations are the most significant binding constraints to private investment in Buenos Aires. These two factors bring us back to the earlier point on whether it is possible to approach productive development policies from the sub-national level. After all, policies related to these factors - taxes and labor regulations - tend to be largely determined at a national level, over which the city has little-to-no influence. How can these constraints be circumvented in the absence of national reforms? Our research has produced two important insights that might shed some light on this question.

First, when comparing Buenos Aires with peer cities in terms of tax regimes, we observe that most of the additional tax burden comes from a municipal tax: the gross income tax (IB, for its Spanish acronym - ingresos brutos). As its name indicates, this tax is imposed on companies' gross income; it is levied at each stage of the chain, based on the gross value of the sale. Although IB is not levied on exports, it might prevent businesses from pursuing investments that cater to domestic demand and inhibit the process of learning-by-doing and evolution that eventually allows them to tackle international markets.

Second, even though labor regulations are indeed a country-wide constraint, the city does have policy options at its disposal that can potentially help overcome them or mitigate their impact. One way to achieve this is the promotion of company-worker-union labor agreements that do not automatically extend - as is the case, presently - to the rest of the sector. Another alternative is to leverage on the city's already existing Economic Districts, and extend their current benefits - tax discounts, property subsidies, and access to talent - to also include differentiated, less stringent labor regimes.

Finally, another policy option is to identify and support export diversification opportunities that are less exposed to the active constraints we've identified. For example, as the gross income tax is not uniform across industries, we might consider industries on the lower end of the rate spectrum to be 
more viable than sectors subjected to a higher rate. As to labor regulations, we know that businesses with less than 100 employees in Buenos Aires face a differential labor regulation burden. Based on international data at the industry level, we can, for instance, estimate the tendency of businesses to organize around units of less than 100 employees worldwide, and consider these amongst the initial target of productive development policies.

In order to focus the efforts of productive development policies on a smaller number of industries with high potential, we have ranked the sectors that resulted from our Economic Complexity analysis according to viability and attractiveness variables. On the viability axis, we have incorporated the capacity of the selected industry of bypassing the binding constraints (their exposure to lower rates of gross income tax, and their propensity to organize around units of less than 100 employees), together with the dependence on occupations that are relatively abundant in the city, the availability of intermediate inputs required by the industry, and the relative strength of their presence in Buenos Aires today. On the attractiveness axis, we have considered the capacity of the industry to mobilize foreign direct investment, its export propensity, the ability of industries to break into global value chains, and the degree to which they employ women (to reduce the observed gender participation gaps observed).

We have grouped all industries into six themes or clusters. As it tends to happen with large modern cities like Buenos Aires, the majority of export opportunities are concentrated on themes related to the service sector: Creative industries, financial services, health services, business services, IT services and tourism. We have analyzed each industry within each them and preliminary assigned it to different prioritization phases based on their relative viability and attractiveness.

We have also worked with CEPE and the Development Unit of the Secretary of Finance of Buenos Aires in devising two different institutional mechanisms to tackle constraints in high-potential sectors depending on whether they are already present in Buenos Aires (intensive margin) or not (extensive margin). For the former, we suggest the creation of productivity task forces, temporary public-private working groups at the sector level, that identify constraints, propose collective solutions, define actions and monitor their implementation. For sectors along the extensive margin, we suggest strengthening the function of investment promotion within the city's government. The investment promotion process we propose shares some features with the productive task forces method, but must be organized in a way that can perform similar functions - understanding the sector, identifying the most binding constraints, designing and coordinating implementation of actions aimed at overcoming them, and communicating them effectively - when the relevant actors are absent from the domestic context.

We hope our research has contributed the pillars for shaping a new productive development policy, but as it tends to happen, the key to unlocking Buenos Aires's potential and propelling the city into an independent engine of growth depends crucially on the soft skills of the institutional capacity. We have modeled and designed these policy inputs following the Growth Lab's own experiences in previous research-based policy engagements in other places and based on the literature that has 
documented them. Together, we have worked to adapt them to the particularities of the context of Buenos Aires. Ultimately, the successful development and implementation of policies for inclusive and sustained growth is born out of a learning-by-doing, dynamic process, involving successive experimentation, evaluation, and adaptation.

This paper is divided into five sections, including this executive summary. In Section II we summarize Buenos Aires's recent growth trajectory, economic structure, and discuss the city's competitiveness at an aggregate level and at the industry level. Section III uses principles of differential diagnosis to identify the most binding constraints faced by companies operating in Buenos Aires. These, in turn, represent the policy areas most prone to deliver the largest growth impact though reform efforts. Section IV describes Buenos Aires's productive structure and identifies potential export industries that can leverage upon the knowledge base that the city already possesses. In this section we also suggest criteria for prioritizing efforts to develop these industries. Finally, Section $\mathrm{V}$ brings together the main findings of our analysis, summarizing its conclusions and presenting inputs for designing policy recommendations. 


\section{Buenos Aires' Growth Performance}

Over the past two decades, Buenos Aires's growth trajectory has experienced two distinct periods: one of accelerated growth (2004-2011) and one of stagnation (2011-2017). During the growth period, per capita gross regional domestic product (GRDP) rose by an annual rate of $6.2 \%$, while the real average wage increased at a rate of $4.8 \%$ per year. During the stagnation period, GDRP fell by a yearly rate of $0.1 \%$, while real average wages rose by a rate of $1.1 \%$ per annum. ${ }^{1}$

At first glance, it would seem that Buenos Aires's growth trajectory could be easily understood as a consequence of Argentina's economic performance. Although the rest of the country does show concurrent periods of growth and stagnation, there is a stark contrast in their rates. During the upswing, Buenos Aires grew at a rate far greater than the rest of Argentina (6.2\% compared to 3.6\%), while, during stagnation, its GRDP shrank less (-0.1\% compared to $-1.1 \%)$, as shown in Figure 1. It stands to reason, then, that national trends alone are not sufficient for explaining Buenos Aires's economic resilience in the context of national cycles of booms and busts.

An alternative hypothesis for interpreting Buenos Aires's divergence from national performance is the existence of a positive composition effect. Buenos Aires's more favorable growth trajectory may be driven by the predominance of sectors within the city that experienced more accelerated growth during the expansion phase and less decline during the deceleration phase. If this were the case, sectors in which the city is particularly intensive sectors should have grown at a rate comparable to that found in the rest of Argentina. However, upon observing the behavior of the most prevalent sectors in Buenos Aires, we notice that this is not the case. For example, while "hotels and restaurants" and "real estate and business services" in Buenos Aires grew by 75\% and 40\%, respectively, between 2004-2017, their growth in the rest of the country was just $25 \%$ and $10 \%$. Therefore, the composition effect alone also falls short in explaining the difference between the economic trajectory of the city and that of the country.

To quantify how different factors contributed to Buenos Aires's economic trajectory, we carried out a growth decomposition exercise. During the growth period, 39\% of Buenos Aires's expansion can be explained aggregate national trends, whereas 16\% was driven by a composition effect. The remaining 45\% could be attributed to Buenos Aires's higher "competitiveness" relative to the rest of Argentina in certain sectors, namely real estate and business services, financial intermediation, and construction (Figure 2). This differential performance could also be characterized as a place-specific effect in these industries. This place-specific effect has allowed the city's economic performance to partially diverge from the rest of the country's and is the main reason behind Buenos Aires's favorable performance during the upswing and the deceleration periods.

1 Employment displayed a similar pattern. During the growth period, the employment rate rose 8.3 percentage points (pp) and the unemployment rate fell by 11.1 p.p. Over the stagnation period, employment fell by 0.7 pp and unemployment rose by 3.6 percentage points. 
Figure 1: Trends in per capita GRDP (2004-17, 2004=100), Buenos Aires and the rest of the Argentina

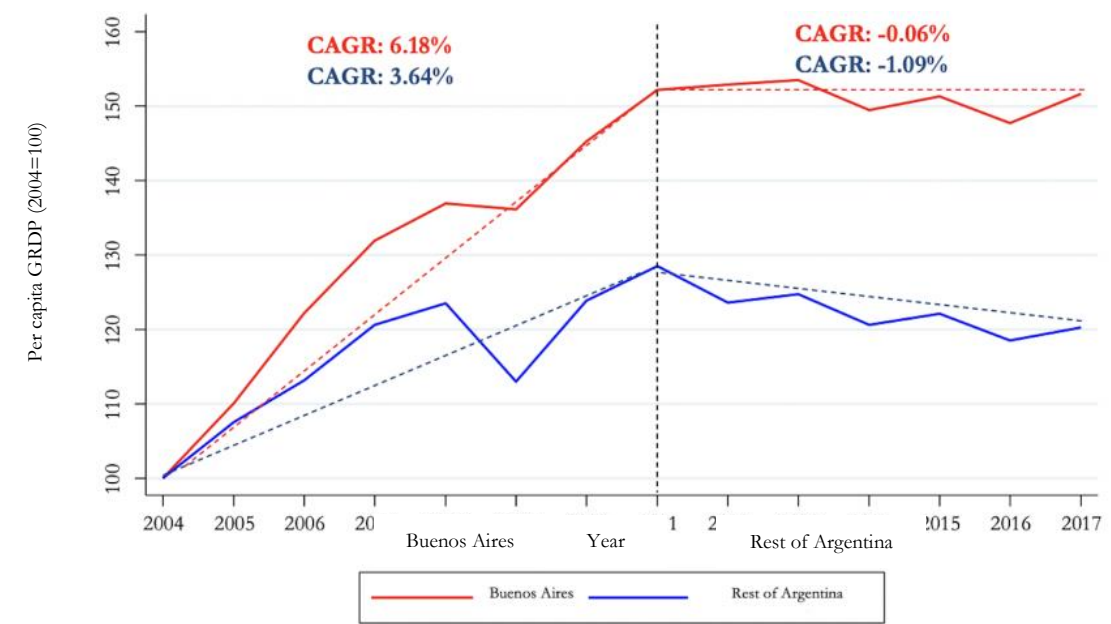

Source: Authors' calculations based on official data from Buenos Aires and INDEC.

Figure 2: Breakdown of competitiveness effect / place-specific effect by sector (2004-17), Buenos Aires to the rest of Argentina

10 largest and smallest percentages, by industry
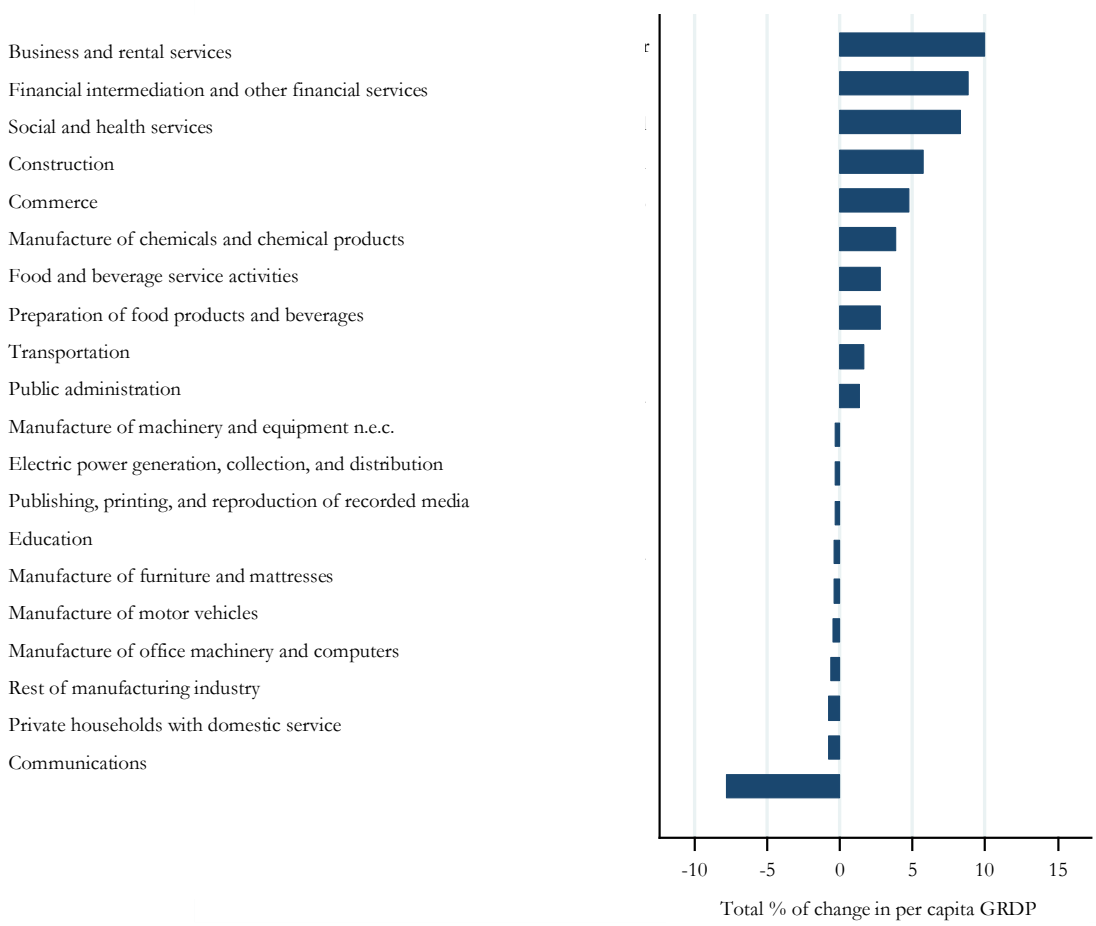

Source: Authors' calculations based on official data from Buenos Aires and INDEC. 
Buenos Aires's favorable resilience relative to Argentina's does not in itself mean that the city has excelled in terms of economic performance. If we compare the city's trajectory with that of its regional peers, ${ }^{2}$ we find that it grew more than most during the expansion period, but that its level of stagnation afterwards was such that, in the aggregate, its rate of growth only outperformed that of its Brazilian counterparts Rio de Janeiro and Sao Paulo (Figure 3, a).

A possible explanation for Buenos Aires's lower growth as compared to its peers could be that the city has a per capita GDP that is almost twice the average per capita GDP of the region's reference cities. Thus, one might surmise that after Argentina's post-crisis rebound in in the early 2000s, Buenos Aires simply continued along a path of more moderate expansion, typical of cities that boast a higher level of per capita income. However, upon comparing Buenos Aires's recent growth with that of its international peers (whose per capita GDP is, on average, twice that of Buenos Aires), the city had the worst performance of the group (Figure 3, b).

Figure 3: (a) Trend in per capita GDP (2004-18, 2004=100), Buenos Aires and regional peers; (b) Trend in per capita GDP (2011-18, 2011=100), Buenos Aires and international peers

(a)

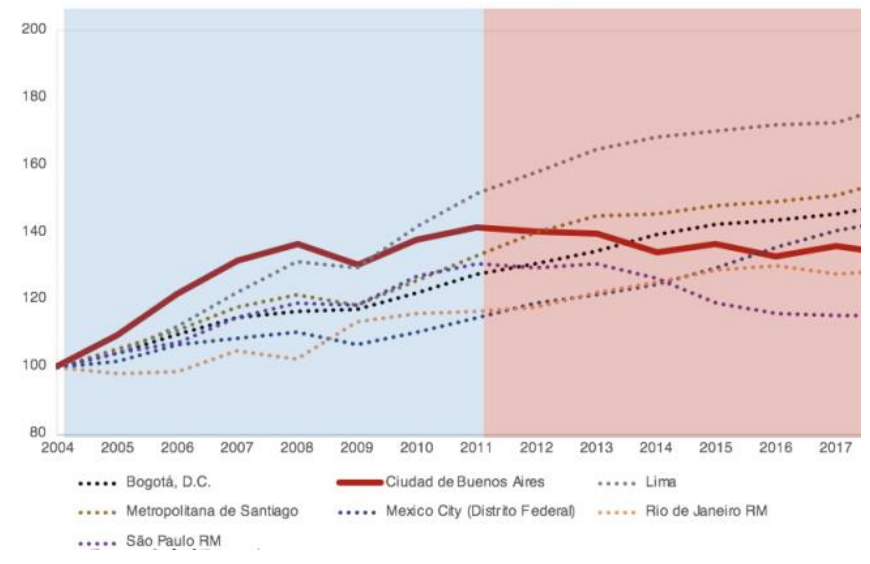

Source: Oxford Economics (b)

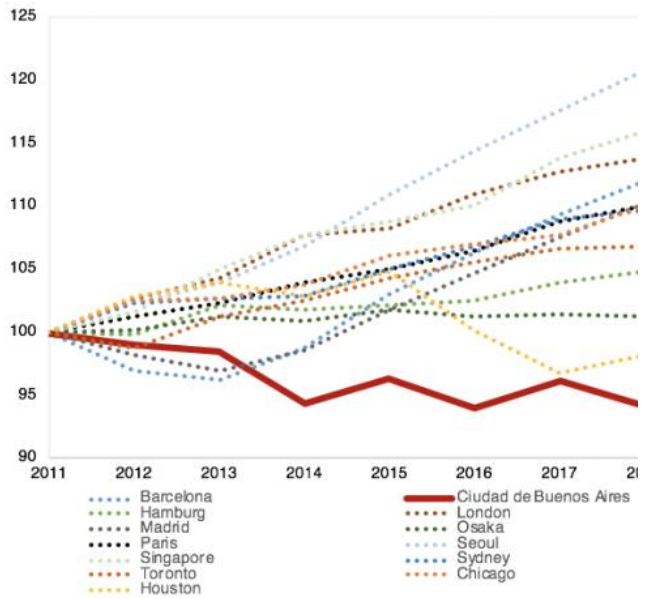

2 To create the groups of regional and international peers, we first selected the 15 most complex countries of Latin America and the 50 most complex in the world according to the Atlas of Economic Complexity. Then we eliminated the countries that didn't have at least one metropolitan area with more than five million inhabitants. Next, we discarded those for which the representativeness of the Dun \& Bradstreet and fDI Markets datasets were inadequate or insufficient. Then, we calculated similarity metrics between Buenos Aires and the cities belonging to this sample of countries in terms of scale and composition, both for employment and activities associated with foreign direct investment (FDI), using data from Dun \& Bradstreet and fDI Markets, respectively. According to these 4 metrics, we ranked the cities, keeping only the two most similar to Buenos Aires for each country considered. Finally, we created the groups of regional peers (Bogotá, Mexico City, Lima, Monterrey, Rio de Janeiro, Santiago, and São Paulo) and international peers (Barcelona, Chicago, Hamburg, Houston, London, Madrid, Osaka, Seoul, Singapore, Sidney, Paris, and Toronto). 
This variance in economic performance across international peers could be linked to the varying ability of cities to diverge from their respective national trends. Although Buenos Aires certainly outperformed the rest of the Argentina, cities in other parts of the world were able to distance themselves even further from the performance of the rest of the country. As compared to the reference cities, Buenos Aires ranks second lowest in its ability to decouple from its national trend. This might be explained, in part, by the fact that other cities have more access to global markets than Buenos Aires, thus reducing their dependence on local demand. Note that Buenos Aires's exports per worker as a proportion of GDP per capita are the lowest among all members of the benchmark group ${ }^{3}$ (Figure 4).

Figure 4: Exporting and disconnecting capacity, Buenos Aires and peers

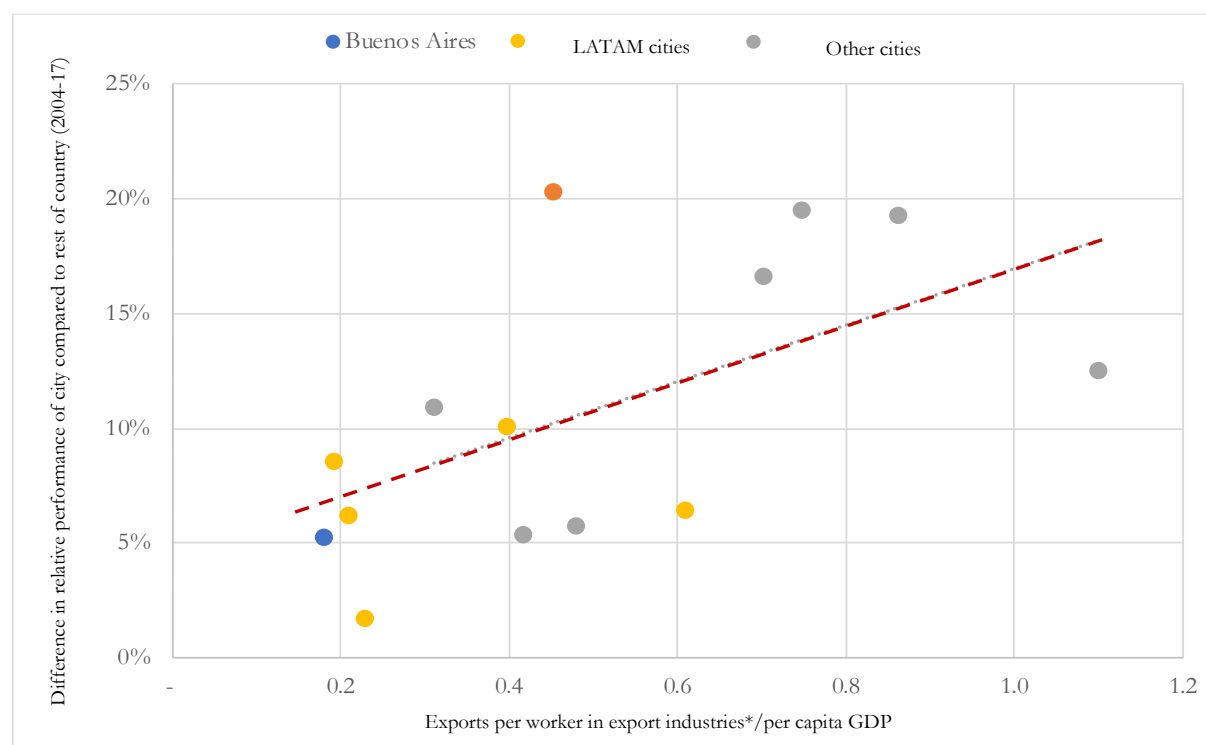

Source: Authors' estimates based on Oxford Economics, UN Comtrade, the World Bank, and Dun \& Bradstreet.

According to several metrics, Buenos Aires is also less internationally competitive than its regional and international peers in the majority of sectors in which it displays intensiveness in terms of exports: ${ }^{4}$ Business and technological services, chemicals and plastics, travel and tourism, and vehicles. If we

3 To estimate the exports of each reference group member, exports of goods and services at the national level recorded in the Atlas of Economic Complexity were assigned to the different cities according to the portion of domestic employment in the sector that each city represents according to Dun \& Bradstreet. Due to the varying levels of job formality in mining and agriculture, exports from these sectors were not considered.

4 To identify the industries that are "present" in a place, one alternative is evaluating the relative intensity of its exports. More specifically, the methodology is based on the concept of revealed comparative advantage (RCA), which measures a sector's relative size at a location. In this case, it is calculated as the ratio between the industry's exports at the location (city) and the same industry's exports in its peers. If this ratio is greater than 1 , one can say that the location has "presence" in the industry, which means that the place is relatively more intensive in this activity than the average location. 
leverage the exports per worker metric (Figure 5) to rank the city's competitiveness in these sectors, we find that Buenos Aires only performs above average in tourism and does not rank within the top two spots in any of the activities. Alternatively, when approximating competitiveness through a market-share metric (Attachment 1), we conclude that Buenos Aires (highlighted in red) does not represent more than $3 \%$ of any of its reference peers' total exports in any sector, and that it only ranks among the top two spots for the region in business services. Finally, if we use a metric for participation in foreign direct investment (FDI) focused on knowledge-intensive activities, such as R\&D centers, head offices, and business service centers, we find that Buenos Aires does not attract more than 1.5\% of total investment going to peer cities, and that it only ranks second in the region in the case of business service centers.

Given these findings, it is likely that policies aimed at strengthening Buenos Aires's export profile could prove a key potential driver for the city's sustainable economic development. Export-led growth and diversification can be achieved by improving competitiveness in industries that already exist in the city (intensive margin), or by promoting new high-impact economic activities (extensive margin).

Figure 5: Exports per worker in sectors in which Buenos Aires is intensive (2016), Buenos Aires and peers
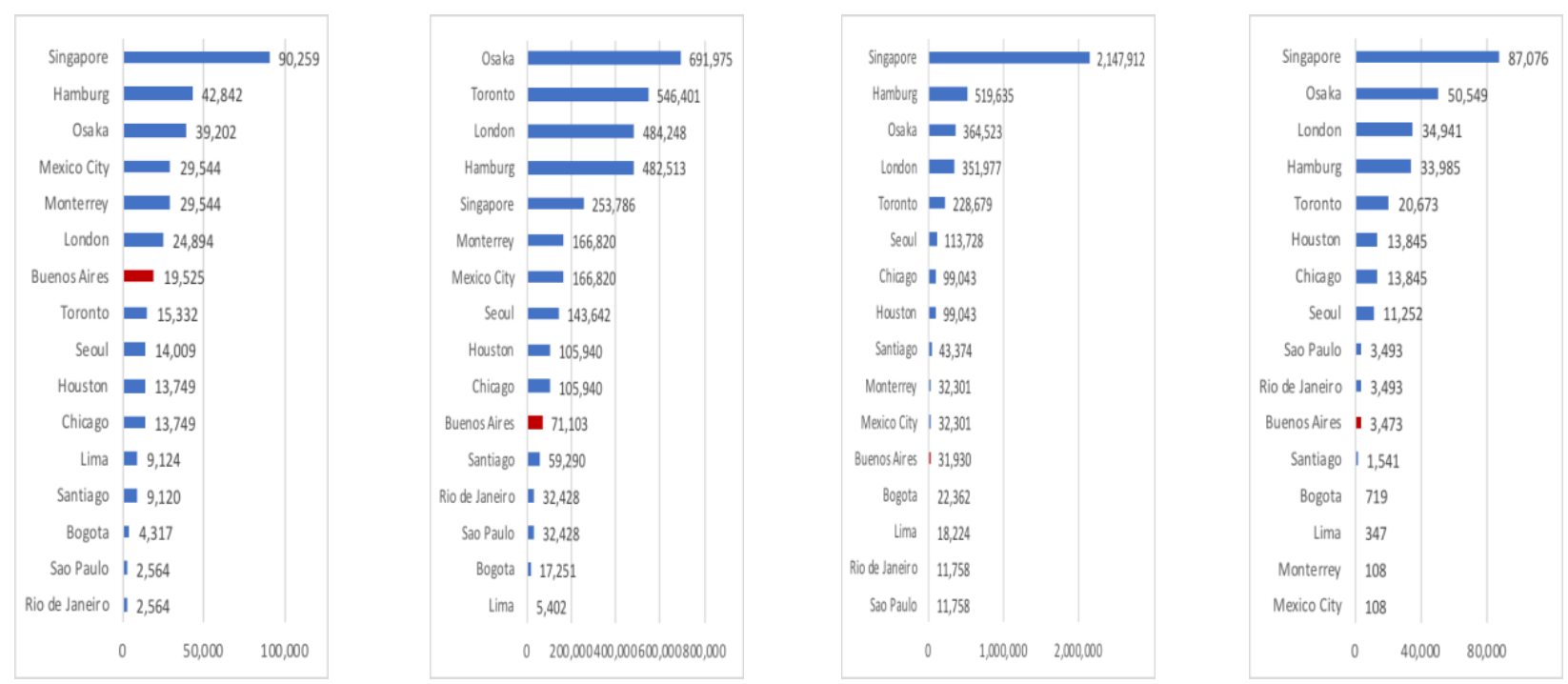

Source: Authors' estimates based on UN Comtrade, IMF, and Dun \& Bradstreet. 


\section{Most Binding Constraints to Economic Growth ${ }^{5}$}

The first step in outlining a policy agenda to jumpstart Buenos Aires's productive development is to identify the most binding constraints faced by companies operating in the city. To do this, we leverage the principles of Growth Diagnostics described in Annex II, whereby the different inputs or factors that affect growth are considered to be compliments rather than substitutes. The logic is that the overall performance of a place - in this case, the city Buenos Aires - is the result of a production function which requires a series of inputs that tend to complement each other. The immediate implication is that all inputs must be present to some extent. Reforms within a specific area will therefore only have an impact to the degree that the input targeted is actually the binding constraint for the relevant production function. This approach does not exempt the need for improvements in other policy areas. However, it is argued that said improvements would not be sufficient in promoting sustainable growth in the absence of reforms that directly or indirectly address the main constraints identified.

Based on this framework, after testing for the four principles of differential diagnosis on all inputs, we identified two likely binding constraints to Buenos Aires's growth: tax rates and employment regulations. Due to the scarcity of publicly available data at the sector level, it is difficult to specify the extent to which these two constraints differentially affect either existing sectors or yet-to-be-developed sectors. Therefore, additional institutional efforts are likely needed to identify the heterogeneous impact of such constraints at the sectoral level.

\section{Tax Rates}

Buenos Aires's taxation system is particularly onerous and may be hindering the development of productive activities in the city by discouraging investment and stimulating informality. According to Doing Business (2019), Argentina's nominal tax rates are the highest among its regional peers and translates into far higher effective rates than those found in Latin America and the world. The report estimates that a company based in Buenos Aires pays the equivalent of $106 \%{ }^{6}$ of its profits in taxes, whereas no other city in the world has an effective rate higher than $72 \%$ (Figure 6 )

The main driver behind Buenos Aires's relatively high tax burden is its gross income tax. In addition to being quite unusual in the region - Bogota is the only other regional peer that levies it - the average gross income tax rate in Buenos Aires is very high (3\%), nearly tripling that of Bogotá.

5 This section only presents the main Growth Diagnostic findings for Buenos Aires. It is worth mentioning that, in applying the Growth Diagnostic framework, we tested all potential constraints as described in the Hausmann, Rodrik, and Velasco (2005). We only present here those that were identified as the most binding constraints. Results for the other factors are available from the authors upon request.

6 Galiani and Serrano (2019) showed that this metric is probably not a precise measurement of the tax burden to which companies are actually subject and, to the contrary, tends to overestimate it. However, they argue that it does provide useful information about the relative efficiency of tax systems, particularly by measuring variations following tax reforms. 
In addition, the income tax scheme implemented in Buenos Aires is particularly distortionary, as it does not allow for inflation adjustment and its taxable base is determined before profits (the collected sum may even exceed actual profits for some companies). According to the 2017 Enterprise Survey, $37.7 \%$ of the city's companies consider tax rates to be their main obstacle. Tax rates were the only constraint to have garnered $15 \%$ of all comments in the report.

In order to determine whether agents less intensive in the factor - in this case, companies facing a lower tax burden - tend to have a favorable performance, we compared outcomes for exporting companies to non-exporting companies within the same industry, since the former are exempt from the gross income tax. ${ }^{7}$ Given the lack of public data on the profitability of individual companies, we used the number of employees as a performance metric. In other words, we assume that companies that are able to hire more workers are more successful. If the gross income tax represents an active constraint on economic performance, then we would expect to find that exporting firms would be able to hire more workers than non-exporting companies within the same economic sector. Moreover, we would expect the difference between exporting and non-exporting firms in Buenos Aires to be significantly greater than in peer cities that do not experience this differential tax treatment.

Our findings suggest that, on average, export companies tend to hire more employees than nonexporting companies. Among regional peers, export companies are able to hire - on average - 3.35 times more employees than non-exporting companies, while among international peers, export companies are able to hire 2.21 times more employees than non-exporting firms. However, in Buenos Aires, this ratio is 5.8 (Figure 7), revealing a gap between exporting and non-exporting firms that far exceeds regional and international reference points. These findings suggest that the tax burden may be significantly limiting the performance of non-exporting firms.

The effects of the gross income tax scheme over economic activity in Buenos Aires can be also assessed by considering the strategic decisions undertaken by agents to circumvent its negative impact. Such is the case of self-employed professionals. While individuals conducting their professional activity in Buenos Aires are exempt from paying gross income tax, those working within the Province of Buenos Aires are not. In studying residence and employment patterns of the self-employed during the 2011-2018 period, we found that professional self-employed individuals living in the conurbano area (Area of the Greater Buenos Aires that is part of the Province of Buenos Aires, but not the city of Buenos Aires) were 9 percentage points more likely than other self-employed individuals in the same area to conduct their economic activity in Buenos Aires. This difference persists even when considering other factors that could explain the decision or ability of workers to conduct their business in Buenos Aires, such as the district of residence, the nature of their activity, their level of income, and other demographic variables.

7 The portion of their sales that is exported.

Emerging Cities as Independent Engines of Growth: The Case of Buenos Aires 
Figure 6: Tax rates as percentage of profits and identification of tax rates as the main obstacle (2017), Buenos Aires and world capitals

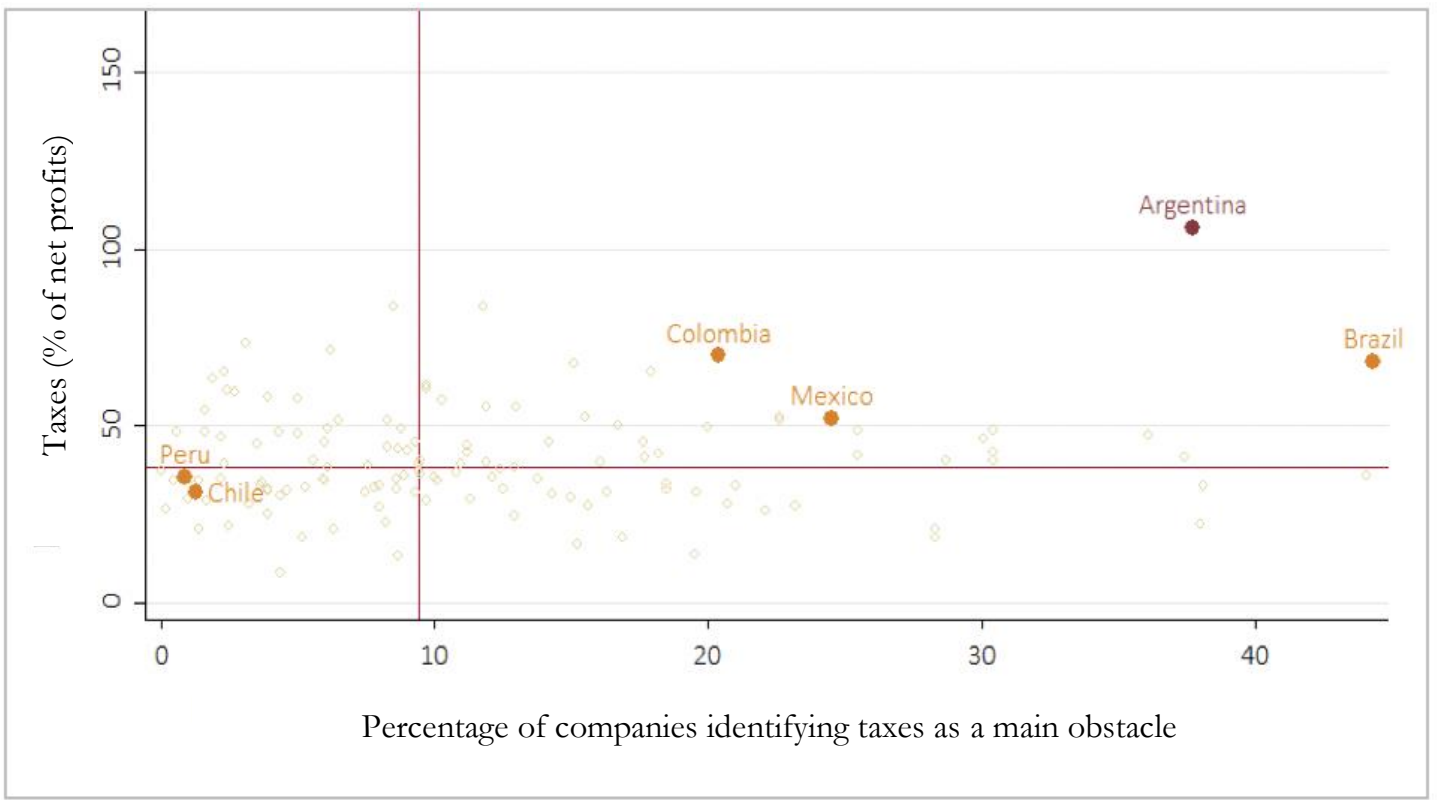

Source: Enterprise Survey (2017), Doing Business (2019)

Figure 7: Size (employment) ratio between exporting and non-exporting companies (2015), Buenos Aires and international peers

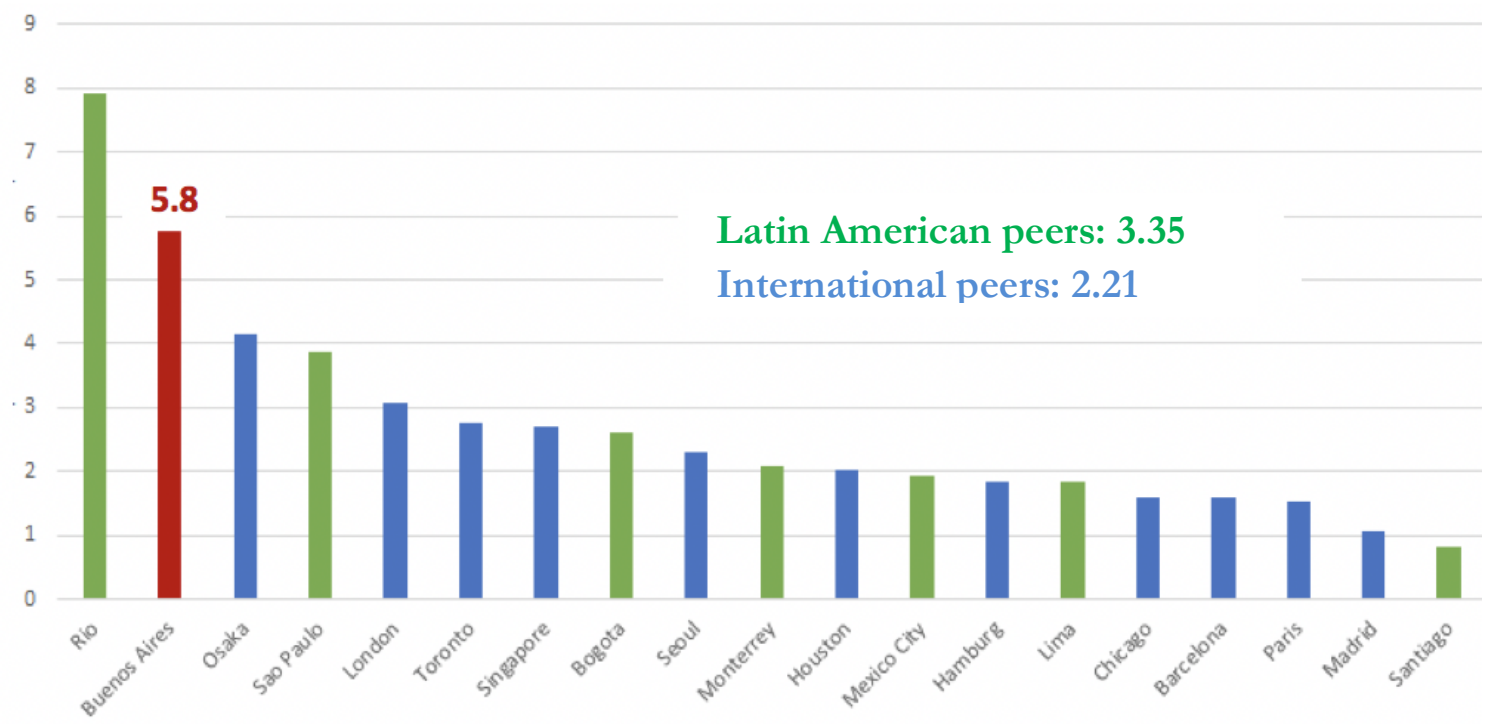

Source: Authors' calculations based on Dun \& Bradstreet. 
The case of Economic Districts offers another example of this type of tax-driven strategic behavior by economic agents in Buenos Aires. These districts offer a range of benefits - including temporary gross income tax exemptions - to companies that conduct certain types of economic activity (audiovisual production, information and communication technologies, among others), within a specific territorial area. If, as previously stated, taxes represent a binding constraint on economic activity, then we would expect to find that companies already operating in the city would seek to relocate to the relevant Economic District in order to receive this benefit.

District censuses conducted by the Statistics and Census Department of the Argentine Ministry of Finance (2016) show that 57\% of the business operating in the Technological and Audiovisual Districts relocated an existing establishment. Although it could be argued that these relocations are the result of economic actors motivated by potential agglomeration effects, in the case of technology firms (where the relocation of establishments represents $63 \%$ of the business operating in the Technological District), there is a greater agglomeration firms and employees in the sector in other areas of the city outside of the Economic District; making agglomeration an unlikely driver for the relocation.

\section{Employment Regulations}

Excessive burdens imposed by labor regulations can have a negative comparative impact on the scalability and competitiveness of firms, disincentivizing investment, and encouraging informality. A wide range of metrics illustrate the high costs associated with employment regulations in Argentina. According to Doing Business (2019), employment tax rates in Buenos Aires are almost twice that of the regional peer average (23\% compared to $12 \%)$ and rank $3^{\text {rd }}$ highest among international peers surpassed only by rates in Spanish and French cities. Similarly, severance pay for layoffs remains the highest among all international peers, and the mandated advance notice period for dismissals is only surpassed, among international peers, by German cities (Figure 8).

In terms of perception, according to the Global Competitiveness Index (2017), Argentina has the third worst performance in the world regarding hiring and dismissal costs, as wells as the fourth worst performance worldwide in terms of the effects of employment taxes as an incentive for formal employment (Figure 9). Similarly, the country has the worst or second worst performance among international peers in 10 of the 12 variables considered, most notably, cooperation in employeeemployer relations, costs associated with layoffs, labor market flexibility, and wage flexibility.

Distortions in the employment regulatory framework may also give rise to contentious employeremployee relations. In this regard, according to the International Labor Organization (ILO) (2017), 
Argentina had the second highest number of strikes or firm shutdowns in the world, and the largest number of employees involved in them. ${ }^{8}$

Finally, 14.5\% of the firms responding the Enterprise Survey in Buenos Aires (2017) perceive employment regulations to be their main obstacle, making them the second most cited concern in the report, after taxes.

In order to determine whether the agents least affected by employment regulations tend to be relatively more successful, we contrasted employment in sectors prone to be organized around small firms with employment in sectors more likely to be structured around large companies. The identification strategy of this test exploits the fact that smaller companies - specifically, those with less than 100 employees - are subject to relatively more lenient regulations and less strict oversight.

Figure 8: Advance notice and severance pay associated with layoffs (2017), Buenos Aires and world capitals

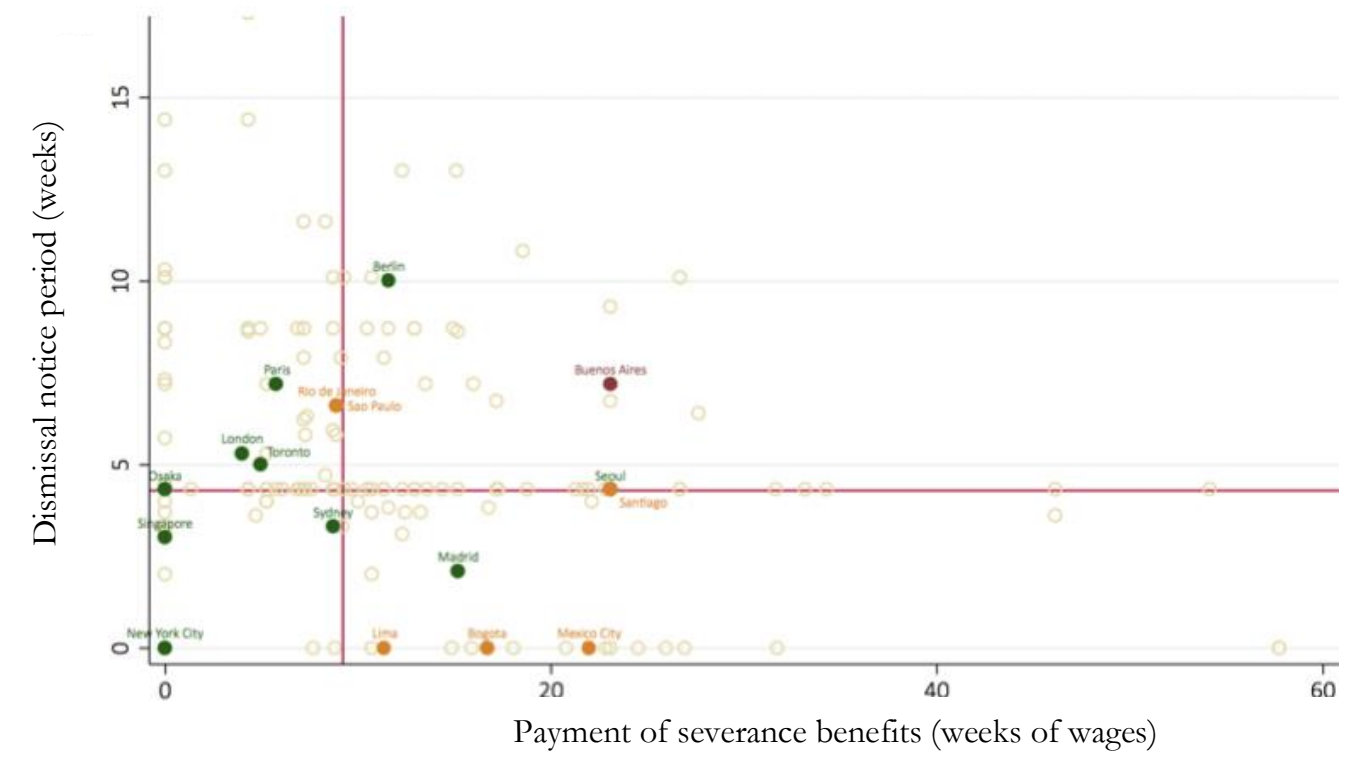

Source: Doing Business (2019)

8 It's worth pointing out that, although ILO statistics refer to labor disputes on the national level, CEPA studies (2018) show that $25.9 \%$ of the country's labor disputes occur in the Metropolitan Region of Buenos Aires, which is equivalent to the proportion of the country's employment located in the region. Therefore, it is probable that labor relations in the Metropolitan Region are as contentious as in the rest of the country.

Emerging Cities as Independent Engines of Growth: The Case of Buenos Aires 
Figure 9: Perception of flexibility in hiring/dismissals and perception of effects of employment taxes on employment incentive (2017), all countries

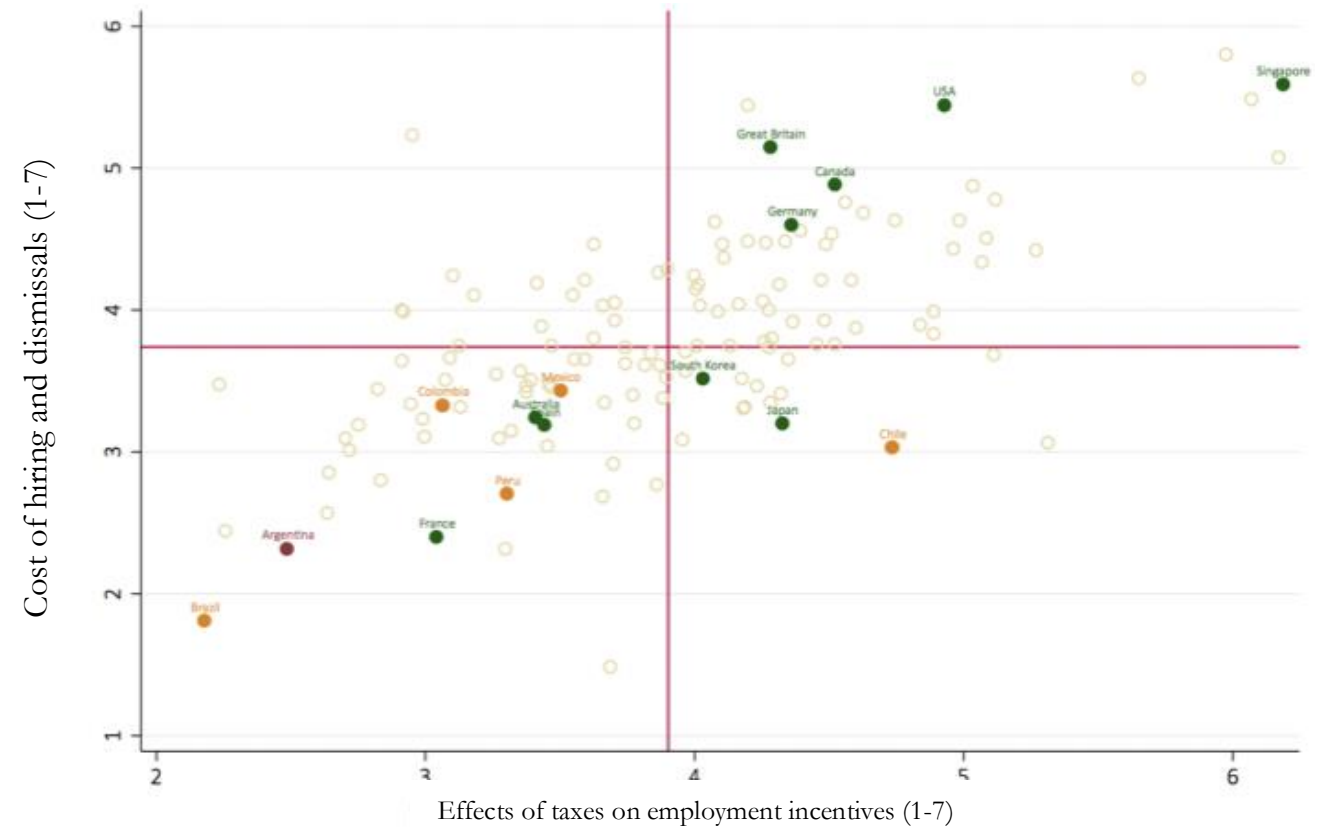

Source: Global Competitiveness Index

Figure 10: Percentage of companies having more than 100 employees by economic sector (2015), Buenos Aires and average among relevant peers

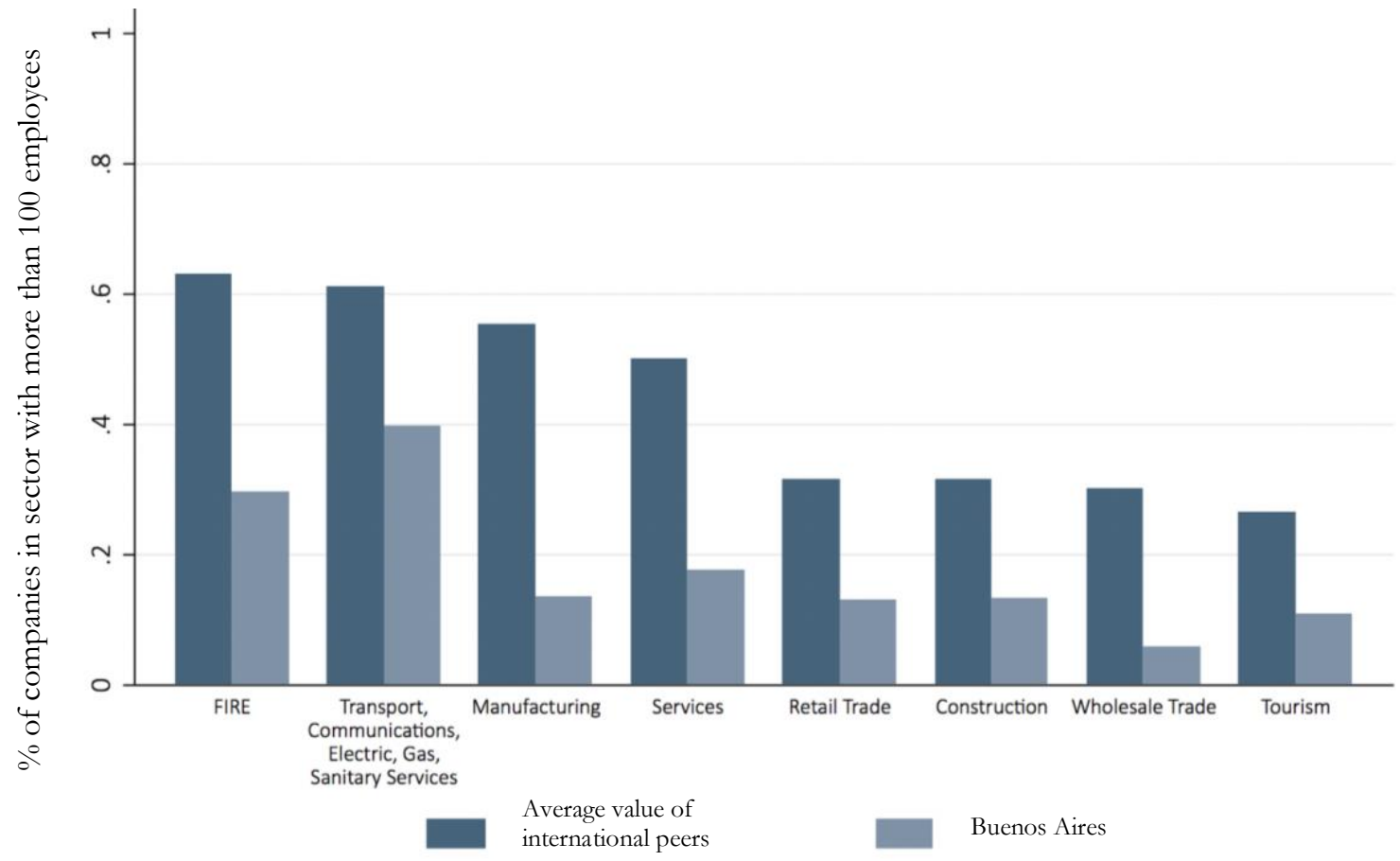

Source: Authors' calculations Buenos Aires on Dun \& Bradstreet.

Emerging Cities as Independent Engines of Growth: The Case of Buenos Aires 
If employment regulations are an active constraint, then companies in Buenos Aires will face significant challenges in achieving a certain scale. Based on this assumption, one would expect that, within the same economic sector, large companies (more than 100 employees) would tend to be less prevalent in Buenos Aires as compared to its international peers. Additionally, if labor regulations are in fact one of the binding constraints, then most of the economic activities in which Buenos Aires displays Revealed Comparative Advantages (RCAs) ${ }^{9}$ would be activities in which large companies are less prevalent.

The results of our analysis show that this is precisely the case. Specifically, Buenos Aires displays a smaller proportion of companies having more than 100 employees than peers for all main economic sectors (Figure 10). Similarly, the city displays RCAs $\geq 1$ for $65 \%$ of the industries in which the share of large companies does not exceed $20 \% .{ }^{10}$ In fact, we found that as the structural proportion of large companies increases within an industry, Buenos Aires's capacity to achieve RCAs decreased (Figure 11).

Figure 11: Proportion of activities in which Buenos Aires shows a Revealed Comparative Advantage according to the structural prevalence of large companies (2015), Buenos Aires

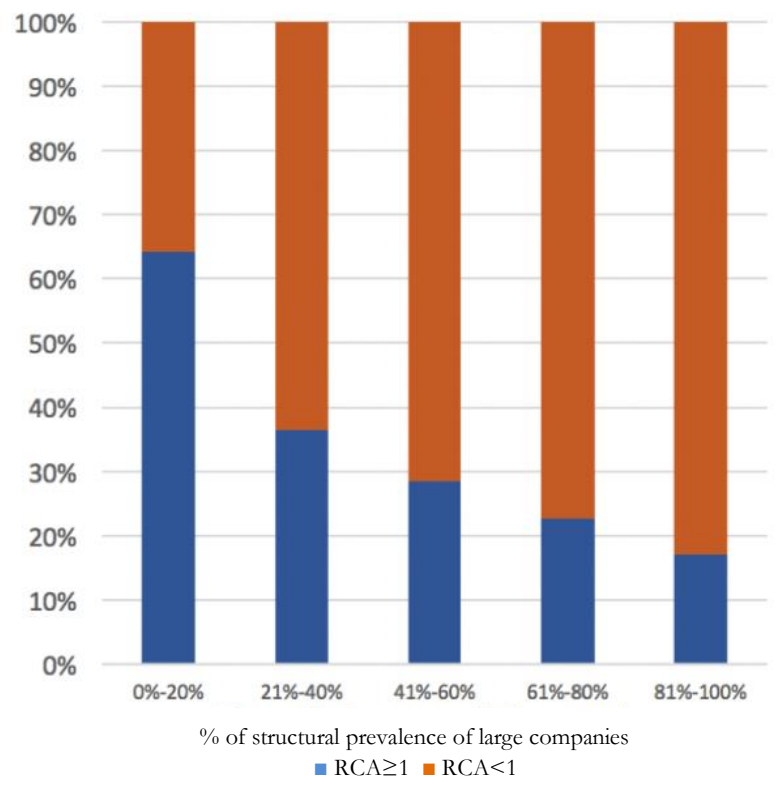

Source: Authors' calculations based on Dun \& Bradstreet.

\footnotetext{
9 RCA $>1$

${ }^{10}$ For this exercise, we used the average value among reference peers as a structural metric. 


\section{Potential Future Constraints to Growth}

The Growth Diagnostic framework stipulates that identifying relevant constraints is an iterative and dynamic process, as it is likely that these constraints will evolve over time. Once the most critical constraints have been eased, other factors that were previously not constraining are likely to become binding. Within this context, having already identified taxes and employment regulations as likely active constraints to growth, our analysis suggests that access to financing and regulatory foreseeability are strong candidates for becoming constraints in the future.

\section{i. Access to Financing}

Although certain firms in Argentina have expressed concern over access to financing, there is currently insufficient evidence to correlate it to hindered economic growth. For example, it is not clear that changes in credit availability or in interest rates are associated with changes in patterns of investment or borrowing. Nor is it clear that economic activities less dependent on financing have a better performance than those more dependent on it.

Nevertheless, according to the Enterprise Survey (2017), nearly 40\% of companies that have at least $10 \%$ foreign capital reported that access to financing is a main obstacle, which makes this factor the principal issue for this type of firm. In a related 2018 study, ${ }^{11}$ PWC found that $76 \%$ of small and medium-sized businesses in Argentina considered access to financing to be one of their most concerning issues, more than doubling the number of firms reporting this same issue in 2017 (30\%).

In addition, there is a large body of evidence documenting scarce financing in Argentina. According to World Development Indicators by the World Bank (2017), Argentina's credit level as a percentage of GDP is far below what one would expect given the level of its economic activity. This applies to domestic credit to the private sector provided by banks, domestic credit to the private sector in general, and domestic credit provided by the financial sector. The same pattern holds in the capital market, measured either by the capitalization of domestic companies and the value of domestic stock transactions as a percentage of GDP, or by the ratio of share turnover. Not only are the financing markets relatively small, they can also be excessively pricey. In fact, nominal lending rates in Argentina are among the highest in the world.

Therefore, it is possible that access to financing is not currently an active constraint simply because there is relatively little demand for it. But as the city's economic growth is reactivated and new or existing companies require financing to expand their operations beyond what their retained earnings allow, this may become a relevant constraint on the development of emerging sectors in the future.

${ }^{11}$ https://www.pwc.com.ar/es/publicaciones/pymes-en-argentina-expectativas.html 


\section{ii. Regulatory Foreseeability}

Regulatory foreseeability refers to the degree to which frequent changes in business norms, such as the introduction of new taxes and withholdings, or the permanence of industrial promotion initiatives and benefits, can be predicted by economic actors. In the context of a growth diagnostic, regulatory foreseeability is not usually considered as a standalone factor, since its impacts on other relevant variables are difficult to assess, as is determining which types of companies are more affected by it than others.

Having said that, our analysis considers regulatory foreseeability to be a potential constraint to growth in Buenos Aires in light of how consistently it was cited as one of the main obstacles to developing productive activities throughout interviews carried out with the private sector. Specifically, business actors reported that constant changes in the "rules of the game" at different levels of government were hindering medium and long-term planning efforts, disrupting investment and expansion decisions, and hampering the ability of export companies to honor their contracts under the originally agreed-upon terms. The absence of regulatory foreseeability was also identified by companies assisting foreign investors in their decision-making as one of the principal deterrents to setting up shop in Buenos Aires. Anecdotal evidence reveals that some Buenos Aires firms with international standing have opted to concentrate their expansion of operations in other countries and are considering moving their headquarters to an alternative city altogether.

Regulatory uncertainty may prevent Buenos Aires from fully taking advantage of the potential boost in economic activity that would arise from easing its active binding constraints. In order for any effort aimed at easing active regulatory constraints to be credible, though, it must be coupled with an unambiguous policy movement that clearly signals medium and long-term stability to economic actors. Otherwise, skepticism will remain over the likelihood that regulatory constraints might return.

\section{Economic Complexity Analysis and Opportunities for Export Diversification}

Our aim throughout this exercise is to provide policy makers with a roadmap for designing strategies that will promote sustained and inclusive growth for the city of Buenos Aires, which may also allow the city to decouple its economic performance from that of Argentina. In order to do so and having already identified the active and potential binding constraints to growth, we must now approximate what a process of productive transformation might look like. Based on the economic complexity framework, ${ }^{12}$ this section studies Buenos Aires's productive structure and complexity indicators using employment data and goes on to categorize thematic areas that provide a roadmap for productive diversification strategy. Once these thematic areas have been identified, we then suggest prioritization criteria for strategically organizing investment promotion efforts.

\footnotetext{
12 For a detailed description of the analysis refer to ANNEX II: Methodological Framework. 


\section{Productive Structure and Complexity Indicators}

The Economic Complexity perspective - first introduced by Hidalgo and Hausmann (2009) contends that the path to economic development involves a progressive accumulation of productive capacities and know-how. The central idea of this theory is that places - in this case, the City of Buenos Aires - reveal their stock of productive know-how through the goods and services they are able to produce, and that future diversification tends to occur along products that require similar productive capacities to those already in place. Over time, locations with higher agglomeration of productive know-how will be able to produce a broader array of goods and services (more diversity) that, on average, fewer places are able to make (low ubiquity). By the same token, places with little agglomeration of know-how will only be able to engage on a narrower set of goods and services (low diversity), that, on average, many other places are able to make (high ubiquity). The Economic Complexity Index is a measure of know-how agglomeration that is derived from the average diversity and average ubiquity of the products and services a place is able to make.

In the case of Buenos Aires, we study the city's productive structure and estimate its economic complexity according to the relative intensity of employment in different industries. The fact that certain industries account for a substantial proportion of employment does not necessarily mean that the city is more competitive or productive than other locations in these sectors. Nevertheless, it does signal that these economic activities might constitute the best use of the available human capital in that place. The underlying assumption is that the same technology of production is used to manufacture the same good - or to render the same service - in different places. This feature is more likely to hold for tradable services, which is the focus of our analysis.

Based on Dun \& Bradstreet ${ }^{13}$ data, we estimate Buenos Aires's distribution of employment at the industry level. The dataset reveals a significant concentration of employment in the service sector (over $40 \%$ of the city's employment) and, to a lesser degree, in manufacturing (around 15\%). Financial and trade activities are also relevant, as they account for slightly less than $10 \%$ of the city's employment.

As we have previously stated, the incentives for the organic accumulation of new productive capacities are endogenous to the capacities already in place and depend on how these can be recombined into new, "adjacent possible," economic activities. The degree of "technological proximity" between industries - how similar the capabilities required for manufacturing or rendering a pair of goods or services are - can be visualized through the Industry Space. Each node represents an industry, which are grouped by sectors, and each node is connected to other industries that are particularly adjacent from a know-how standpoint.

Buenos Aires's Industry Space (Figure 12) gives a snapshot of its current productive structure, showing the results of our employment distribution exercise according to the Revealed Compared

\footnotetext{
13 The D\&B database is updated annually. The specific year used for these calculations Buenos Aires is 2015.
} Emerging Cities as Independent Engines of Growth: The Case of Buenos Aires 
Advantages (RCA) of different industries. The colored circles correspond to the industries in which the city has a high relative intensity $(R C A \geq 1)$ in terms of employment, while the gray circles represent the remaining industries $(\mathrm{RCA}<1)$. As we can see from the prevalence of blue and pink nodes on the space, the sectors with greatest concentration of industries with RCAs $\geq 1$ are "services" and "manufacturing."

Although the productive structure of a place provides important information about the nature of the potential industries that can be developed by leveraging on existing productive capacities, this should be supplemented with indicators describing their relative complexity. Only then can we estimate the sophistication of productive know-how present, and, consequently, the diversification opportunities and potential economic performance that is within reach for that location. We use the Economic Complexity Index (ECI) for this purpose.

To estimate ECI, we calculate the average complexity of industries in which Buenos Aires and its peer cities have RCAs at an aggregate level. According to this indicator, Buenos Aires has a low level of relative economic complexity, placing it at 13 out of 19 cities within the benchmark group.

Figure 12: Industry Space, Buenos Aires
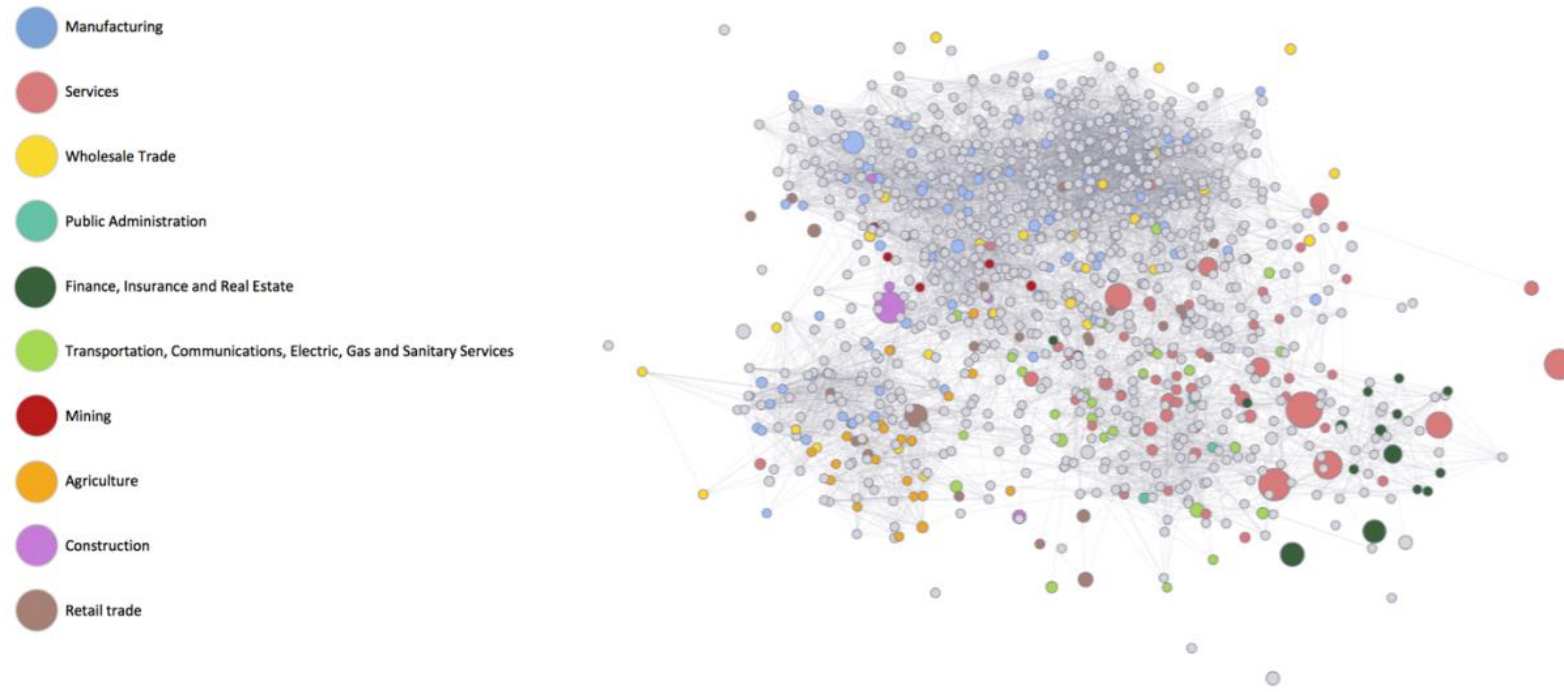

Source: Authors calculations based on Dun \& Bradstreet.

Buenos Aires is not only less complex than most of the reference cities, it is also less complex than one would expect given its level of income, as shown in Figure 13. In other words, its level of income would be considered "too high" for its relatively lower degree of sophistication in productive knowhow. Under these circumstances, in the absence of policy interventions, we would expect Buenos Aires to be at an increased risk of an adverse growth trajectory in the future. In a more proactive scenario, the city might be able to adopt policies to close this gap by diversifying into more 
sophisticated industries that can translate into an economic complexity that is consistent with higher levels of income. The feasibility of this transition will be largely informed by the proximity of Buenos Aires' current productive structure to these new complex industries,.

In this sense, a complementary metric to ECI is the Complexity Outlook Index (COI), which measures how many complex industries are present near a location's current productive capabilities. Hence, places "closer" to producing a larger number of more complex products show higher COI values. Our analysis shows that Buenos Aires has a relatively favorable COI, ranking at 5 out of 19 cities within the comparison group. A high COI implies high potential for diversification and a plethora of alternatives in increasing the overall level of economic complexity. Although Buenos Aires has a relatively less complex productive structure, it is in a favorable position for diversification because the activities in which it shows RCAs $\geq 1$ share a lot of productive know-how with other, more complex activities.

Figure 13: Economic Complexity Index and Per Capita GDP, Buenos Aires and international peers

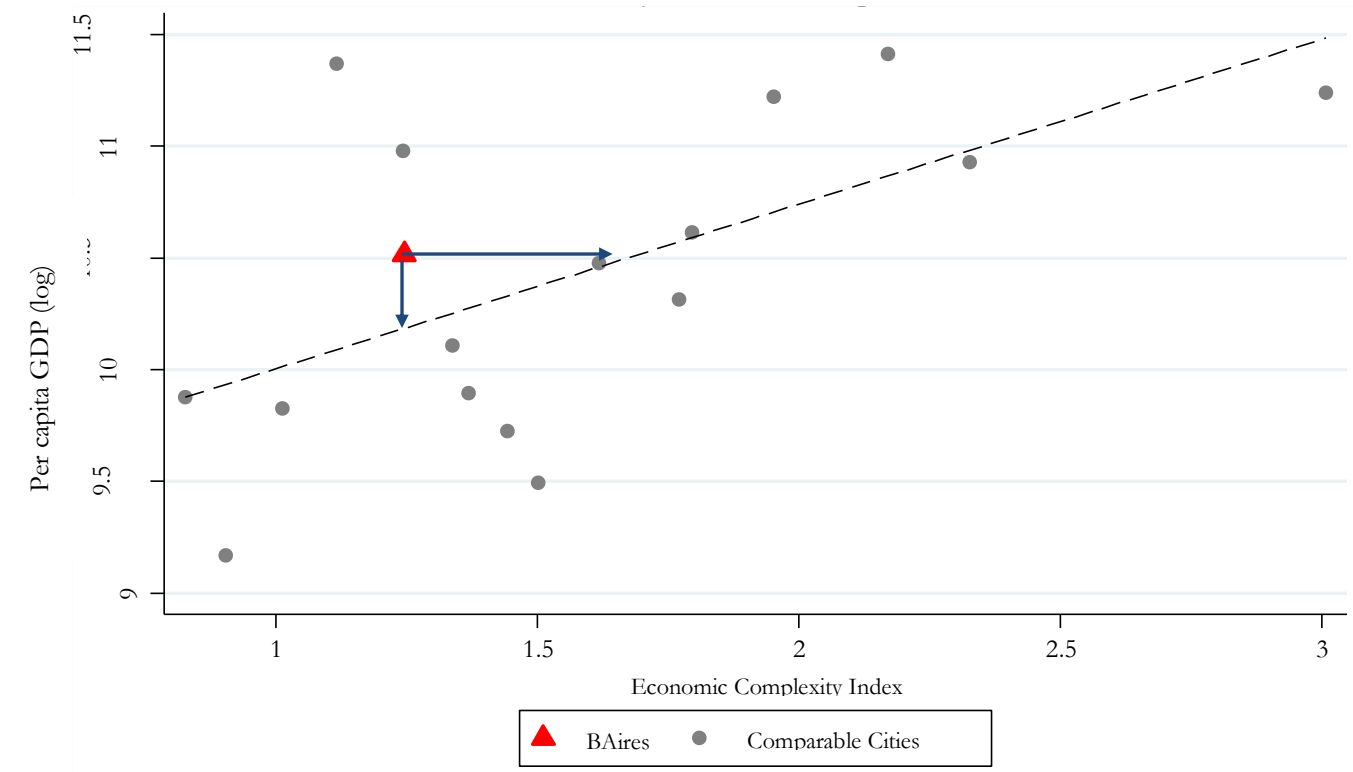

Source: Authors' calculations based on Dun \& Bradstreet and Oxford Economics

The productive transformation process has two components. The first consists of identifying activities that share knowledge with those already existing intensively in the city, but which can add greater complexity to the productive structure (directly or indirectly). The second involves devising strategies to either tackle or bypass the constraints that prevented these activities from developing, in order to efficiently prioritize productive diversification efforts. Therefore, in the next sections, in addition to defining a systematic process for sector identification, we propose a prioritization system that considers complementary feasibility and attractiveness metrics. Having said that, this process is 
largely a theoretical preliminary approximation. Ultimately, the prioritized productive diversification efforts should arise from an iterative and dynamic process carried out jointly by the public and private sectors, in which they simultaneously evaluate available productive know-how and growth constraints in the city.

\section{Diversification Opportunities}

The first step in our identification exercise is defining tradable industries. As its growth trajectory shows, Buenos Aires has been unable to develop sufficient independent growth engines that would allow it to decouple from the national trend to the extent that we observe in comparable cities. Given the significant macroeconomic volatility that has predominated at the national level, export-led citylevel growth may prove to be the most viable option for establishing a more sustainable path to productive development.

The export-led growth that Buenos Aires requires should arise from a combination of industries that already have a significant presence in the city (intensive margin) and absent industries for which global patterns suggest it has latent capabilities (extensive margin). Decoupling growth from national trends will depend crucially on the city's capacity to realize the export potential of both types of industries and become less reliant on domestic demand. We will define intensive margin industries as those in which Buenos Aires has a high intensity of relative employment (RCA $\geq 1$ ), while the extensive margin comprises industries in which the city has a low intensity or no presence at all $(\mathrm{RCA}<1)$. The variables used to prioritize industries are different for each of the two groups.

In a second step, we selected a relatively limited group of industries according to certain economic complexity metrics from among those industries defined as tradable. This is the methodological keystone, as it determines the stage at which an initial group of industries is defined, so they can later be prioritized. The objective of this step is to identify the industries that are "nearby" in terms of know-how, so that the capabilities that the city already possesses can be leveraged as a steppingstone towards other activities of greater complexity and growth potential.

There is, however, an important tradeoff that most places usually face in the context of this exercise. The most complex industries - those with the best strategic positioning on the Industry Space - tend to be located "further away" from currently existing capabilities, while less complex industries tend to be "nearer". The methodology tries to offset this tradeoff by assigning a positive weight to different metrics that capture the tradeoffs between these dimensions. The "distance" variable measures how similar the industry in question is in terms of know-how to those already operating in the city. The second variable is a combination of the Product Complexity Index (PCI), which measures how complex or sophisticated a specific industry is, and strategic value (SV) which measures the extent to which a particular industry can lead the way to other, more complex industries. Based on different weightings of these variables, different strategies can be defined to identify sectors. 
Given Buenos Aires's relatively low economic complexity index, we selected two different strategic approaches, and weighted the three metrics accordingly. More specifically, in the first strategy, which we call "strategic bets," a combination of PCI and SV is assigned a weight of $60 \%$, while distance receives the remaining $40 \%$. In the second, more balanced strategy, these shares are split 50\%-50\%.

These weightings, as well as the aforementioned complexity metrics, were used to score each productive activity in which the city does not have an RCA $\geq 1$ - that is, industries in which the city has a low intensity or that are absent altogether. Based on this scoring system, the 50 industries with the highest score were selected for each strategic approach, resulting in a list of 81 activities (as there is significant overlap in the two sets of results).

For productive activities in which the city has an RCA $\geq 1-$ meaning a high intensity of relative employment - it seems reasonable to assume the distance variable to be 0 , and their SV to have already been captured ("the city is already there"). Therefore, for this category of industries, we only considered the PCI. This means that there is no difference between the "strategic bets" and "balanced approach" sets in this case, and that we simply identified the 50 existing productive activities with the greatest PCI.

Next, the industries identified leveraging the complexity filter - regardless of whether they belonged to the intensive or extensive margins - were grouped into clusters of related industries. The groups with the most industries selected were defined as areas or themes of growth and diversification, which the city may focus on developing. The selected industries that could not be assigned to one of these groups were eliminated from the process, since focusing on industrial clusters has a higher probability of success than focusing on individual industries. This approach reduced the total number of potential diversification opportunities from 81 to 70 , and the set of total activities already present from 50 to 39.

This analysis translated into seven thematic areas, providing a potential roadmap for structural transformation and diversification of Buenos Aires's exports over the coming years: (1) business and professional services; (2) financial services; (3) health services; (4) tourism services; (5) creative industries; (6) IT services; and (7) educational services. Attachment 2 lists the individual industries that each of these themes contains, grouped by more narrowly defined thematic subareas. A description of these thematic subareas as well as some examples of international companies that would fall within this classification can be found in Attachment 3.

\section{Prioritization of Productive Diversification Efforts}

As the previous section illustrates, our approach for prioritizing high-potential export industries in Buenos Aires relies heavily on economic complexity metrics. However, it also considers other relevant, city-specific factors that might influence the viability and attractiveness of the various proposed options. The objective, once again, is to provide policymakers with a guide to the types of inputs that should be examined in order to optimize and organize efforts. Ultimately, industries to be targeted 
should emerge from an iterative and dynamic process carried out jointly by the public and private sectors, taking all the aforementioned factors into account, as well as the policy priorities defined (for example, incorporating more women into the workforce), so as to fully exploit Buenos Aires's competitive advantages and to avoid - whenever possible - the restrictions it faces.

Note that we suggest limiting this analysis to industries in which the city has a low intensity or that are altogether absent, partly due to a limitation in terms of comparability - activities that already exist intensively are, by definition, viable - and partly because the types of efforts required to promote existing and absent industries are quite different. ${ }^{14}$ In this respect, we suggest placing all activities belonging to the intensive margin in what we define as Phase 0 , which implies moving ahead with interactions with private actors and experts from these sectors even before undertaking any diversification initiatives.

To prioritize diversification opportunities in the extensive margin, we suggest considering five viability factors and five attractiveness factors, and assign methods for measuring the performance of each industry along these axes: $:^{15}$

\section{i. Viability Factors:}

- Current presence in Buenos Aires: The greater an industry's current presence in the city, the greater the probability that it faces significant development challenges. Likewise, the presence of local actors of a sufficiently representative scale should allow authorities to obtain relevant information about the particular needs and circumstances of the given industry. The level of an industry's presence in Buenos Aires can be assessed using the RCA.

- Ability to access the occupational vector (those occupations that are generally employed to carry out the activity): A crucial element in developing any productive activity is the ability to access the required occupations. To measure performance in this variable, the system considers the number of occupations deemed to be (i) intensively required by the industry in question and (ii) lacking or inaccessible in the city. The methodology used to make these assessments is explained in detail in Attachment 4.

- Ability to access intermediate inputs: Another essential factor for viability is the possibility of obtaining the intermediate inputs required for its development. The approach for measuring this factor is similar to the preceding factor's and is also explained in detail in Attachment 4.

14 Although the idiosyncratic challenges of activities in the intensive margin can be complex, representative counterparts already exist in the city with whom it is possible to more effectively identify these challenges and agree on strategies for tackling them. In contrast, since activities in the extensive margin do not have sufficient local counterparts, channels of communication are needed with actors not established in Buenos Aires.

${ }^{15}$ Some factors are calculated based on information from the United States because this country has accessible and reliable databases. At the same time, as previously highlighted, this country displays an advanced productive structure and a large group of industries, which could provide a good approximation of how industries interact with each other and what types of abilities they would require when fully developed in Buenos Aires. 
- Ability to be organized around small and medium-sized businesses: As mentioned earlier, employment regulations constitute a possible constraint for Buenos Aires's growth. Thus, if an industry tends to be organized around small and medium-sized businesses - which are relatively less affected by employment regulations - it likely has a greater chance of succeeding in Buenos Aires. Performance in this factor can be approximated using the percentage of employment in the activity concentrated in companies having more than 100 employees, using the average of comparable cities and $\mathrm{D} \& \mathrm{~B}$ data as a reference.

- Current exposure to the gross income tax: High tax rates - specifically, pressures arising from the gross income tax - were also identified as a constraint to Buenos Aires's growth. It follows that industries less exposed to this tax are more likely to develop. Performance in this factor can be estimated using the gross income tax rate applicable to the particular activity. ${ }^{16}$

\section{ii. Attractiveness Factors:}

- Ability to incorporate female workforce: A large part of the labor participation gap between Buenos Aires and its peers is explained by women's low level of participation. If diversification opportunities were to employ more women, then they could serve as a driver for growth and inclusion; therefore, industries that tend to include women could be prioritized. Performance in this factor can be estimated using the percentage of female employment in each industry (using BLS data for the United States).

- Ability to become an export activity: Buenos Aires's proposed growth strategy should be driven by exports. In this respect, if an industry is more likely to be organized to serve international markets, then it is more likely to be able to boost the city's export profile. To measure this factor, the methodology considers the percentage of employment in each industry worldwide that is found in companies reporting that they are exporters (according to D\&B data).

- Ability to participate in global production chains: A core strategic guideline throughout this exercise has favored approaches that can insulate Buenos Aires's growth performance from the rest of Argentina's. Within this context, if diversification opportunities tend to be structured around global productive processes - as opposed to those which only satisfy the local market - they are more likely to be able to help achieve this goal. Performance in this factor can be estimated using the percentage of foreign direct investment (FDI) that is channeled toward global operations (based on data from fDi Markets).

- Ability to attract foreign direct investment at the global level: Direct benefits of FDI such as the inclusion of additional productive know-how to the city - as well as indirect

16 This is an imperfect approximation because tax rates are not assigned using a NAICS classification; therefore, it is necessary to cross-reference industrial systems, which can lead to errors. 
benefits - such as the development of new activities associated with landing these investments - all have a positive impact on diversification efforts. Performance in this factor can be estimated using the total value of foreign direct investment that goes to the set of international peers for each diversification opportunity in the period 2003-2015 (based on data from fDi Markets).

- Ability to attract foreign direct investment at the regional level: The flow of investment to regional peers should, in theory, bring the previously mentioned direct and indirect benefits of FDI closer to Buenos Aires's reach. Performance in this factor can be measured using the total value of foreign direct investment in the set of regional peers that was used for each diversification opportunity (fDi Markets).

Once the performance of each of the ten factors mentioned above for the different diversification opportunities is determined, we can combine this data to assess and score industries according to average viability and attractiveness. To standardize estimated values for comparative purposes, we first calculate the difference between the performance of each industry in each category, and the value for the best performance of any industry in that category. We then divide this difference by the range between the best and worst performing industries in the factor. Lastly, we multiply the resulting value by 10 . Thus, the industry that displays the best performance in the factor gets a standardized value of 10 , and the worst gets 0 . The remaining industries are ranked according to their relative performance.

Standardizing values makes it easier to identify and visualize factors that improve or worsen the viability and attractiveness of different diversification opportunities. An applied example of this method is shown in Attachment 5, regarding performance of the diversification opportunity "TV production and other postproduction services" according to different feasibility and attractiveness factors.

Once the values have been standardized, the scores for viability and attractiveness can be added together to estimate, for each diversification opportunity, a total score for both dimensions. ${ }^{17} \mathrm{Next}$, we suggest prioritizing diversification opportunities in phases, according to the following criteria:

- Phase 1: Those activities having a better-than-average performance in both the viability dimension and in the attractiveness dimension.

- Phase 2: Those activities having a better-than-average performance, either in the viability dimension or in the attractiveness dimension.

- Phase 3: Those activities having a worse-than-average performance in both the viability dimension and in the attractiveness dimension.

The exercise resulted in 39 activities allocated to Phase 0 (intensive margin), 20 activities to Phase 1, 30 activities to Phase 2, and 20 activities to Phase 3 (Figure 14).

\footnotetext{
17 This approach gives the same weight to all factors considered. 
Figure 14: Prioritization of activities by thematic area and thematic subarea, all diversification opportunities

Diversification opportunities

Creative industries

Arts, entertainment, and recreation

Marketing, advertising, and public relations

Data and content dissemination platforms

Audiovisual production and sound recording industries

Health services

Development of drugs and pharmaceuticals

Hospitals and other specialist care facilities

Outpatient healthcare and medical services

Tourism services

Lodging

Travel arrangements, reservation services, and other tourism support services

Restaurants and other food services

Educational services

Higher education

Research and development

Education support services

Continuing, professional, and/or specialist education

Business services

Professional and specialized services

Business support and administrative services

Management, technical, and scientific consulting services

Financial services

Insurance

Advisory services, portfolio management, and other activities related to financial investment

Securities and commodity contracts intermediation and brokerage

Credit intermediation

IT services

Design of computer systems, software, and associated services

Data processing, hosting, and related services

Total

\begin{tabular}{|c|c|c|c|c|}
\hline PHASE 0 & PHASE 1 & PHASE 2 & PHASE 3 & Total \\
\hline 13 & 3 & 8 & & 24 \\
\hline 3 & & 4 & & 7 \\
\hline 5 & 1 & & & 6 \\
\hline 1 & & 2 & & 3 \\
\hline 4 & 2 & 2 & & 8 \\
\hline 2 & & & 11 & 13 \\
\hline \multirow[t]{3}{*}{2} & & & & 2 \\
\hline & & & 5 & 5 \\
\hline & & & 6 & 6 \\
\hline \multirow[t]{2}{*}{3} & 4 & 3 & 1 & 11 \\
\hline & 1 & 2 & & 3 \\
\hline \multirow[t]{2}{*}{3} & 3 & & & 6 \\
\hline & & 1 & 1 & 2 \\
\hline 2 & & 5 & 4 & 11 \\
\hline \multirow[t]{4}{*}{2} & & & 1 & 3 \\
\hline & & 2 & & 2 \\
\hline & & 1 & 1 & 2 \\
\hline & & 2 & 2 & 4 \\
\hline 6 & 4 & 3 & 4 & 17 \\
\hline 3 & 1 & 2 & 2 & 8 \\
\hline 1 & 2 & 1 & 1 & 5 \\
\hline 2 & 1 & & 1 & 4 \\
\hline 8 & 8 & 10 & & 26 \\
\hline 4 & 2 & & & 6 \\
\hline 2 & 3 & 5 & & 10 \\
\hline \multirow[t]{2}{*}{2} & 1 & 1 & & 4 \\
\hline & 2 & 4 & & 6 \\
\hline 5 & 1 & 1 & & 7 \\
\hline$\overline{4}$ & & 1 & & 5 \\
\hline 1 & 1 & & & 2 \\
\hline 39 & 20 & 30 & 20 & 109 \\
\hline
\end{tabular}

Source: Authors' calculations. 


\section{Conclusions and Policy Recommendations}

From 2004-2017, the city of Buenos Aires showed that it was able to partially diverge from the rest of the country in terms of economic performance. It grew at a higher rate than Argentina (6.2\% compared to 3.6\%) during the 2004-2011 economic expansion period and slowed at a somewhat lower rate during the 2011-2017 contraction period (-0.1\% compared to $-1.1 \%)$. However, when compared to peer cities, there seems to be significant potential for further decoupling the city's growth from the country's context. To realize this potential, Buenos Aires must develop institutional vehicles to increase the productivity of its export sector and promote new industries that reduce its exposure to large swings in domestic demand.

On that basis, we have sought to identify the main constraints actively restricting the performance of companies currently operating in Buenos Aires and found significant evidence that these correspond to the tax system and employment regulations. On both fronts, Buenos Aires is at an obvious disadvantage compared to regional and international peers. Therefore, any effort to develop the export sector will probably tend to be initially bounded by these two factors and will consequently require policy interventions aimed at alleviating or avoiding these constraints.

In addition, we studied the accumulation of knowledge present in Buenos Aires, as reflected by the variety of products and services the city is able to offer with Revealed Comparative Advantage. Based on this information, we identified other industries with export potential that require a similar set of capacities and know-how than those already in place. Furthermore, we have grouped this set of activities into thematic areas, which can provide a roadmap for the structural transformation and the diversification of Buenos Aires's export sector in the coming years. Within this context, we have also suggested some criteria for prioritizing efforts to promote the development of these activities.

The opportunities that present the greatest potential for boosting Buenos Aires's export profile lie in the service area: business services, financial services, health services, educational services, tourism, IT services, and creative industries. What follows in this section is a set of proposed policies and institutional mechanisms that city officials can consider implementing in order to realize this export potential.

In essence, the set of inputs we have considered are divided into four large areas, identified in green in the diagram shown in Figure 15, which summarizes the iterative process that we propose: policies aimed at easing constraints, policies aimed at bypassing constraints, the creation of productivity taskforces, and investment promotion. 
Figure 15: Productive development policies for Buenos Aires

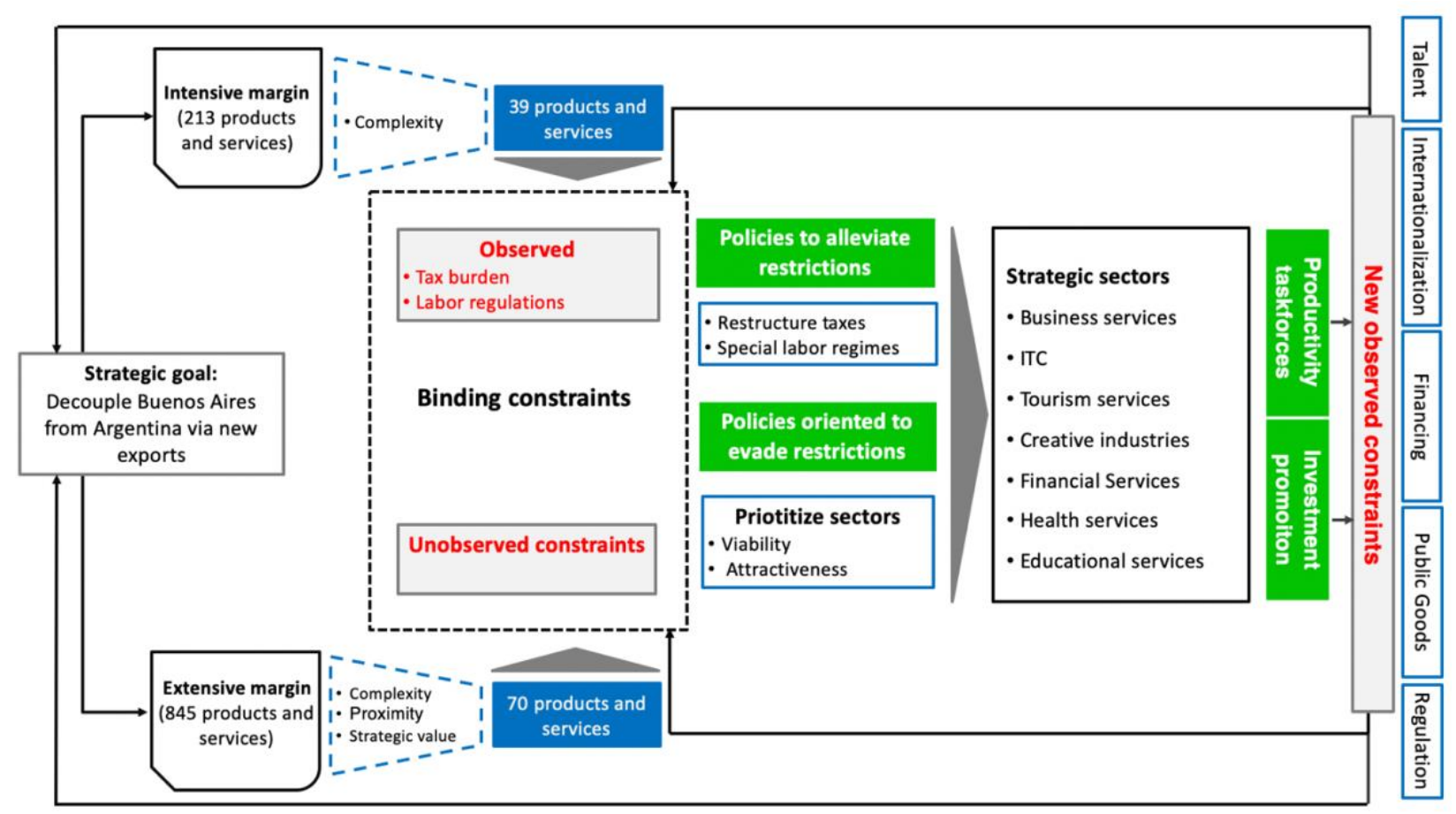

Source: Growth Lab team.

\section{Inputs for Designing Policies Aimed at Easing Constraints}

A provoking assertion emanating from this research, is that regional governments may pursue initiatives at the subnational level which may ease constraints created by national policies over which they generally have little direct influence, such as the tax system or employment regulations.

In the case of Buenos Aires, most of the tax pressure that companies experience come from a municipal tax: the gross income tax (IB, for its Spanish acronym). As its name indicates, this tax is imposed on companies' gross income; it is levied at each stage in the chain, based on the gross value of the sale. Although this mechanism facilitates its collection - it is very difficult to avoid - it ultimately works as an amplifier of the impact on prices observed by the final consumer.

Public finances depend to a large extent on the IB, as it represents around 75\% of Buenos Aires's revenues. For this reason, the only possible alternative for easing it as a constraint is to gradually replace it with other, more progressive tax initiatives that would generate fewer distortions. 
One alternative, would be a value-added tax (VAT), levied on final consumer products that are less prevalent in the basket of low-income citizens, so as to avoid the cascading effect of the IB on prices. A second alternative could consist of an institutional effort to increase the collection of taxes from one of the greatest beneficiaries of know-how agglomerations: real estate owners. Property owners directly benefit from the city's efforts to foster the agglomeration of know-how and productive capacities that makes greater productivity possible, without necessarily contributing to it. If this positive externality is not internalized through taxes, it is equivalent to a sort of an untaxed direct transfer from the city to real estate owners.

Strangely, property taxes are the only taxes in which Buenos Aires displays rates that are similar to the region's average (Figure 16, a), and whose collection is among the least relevant in relation to comparable Latin American cities - ranking second-to-last above Lima (Figure 16, b). Rather than focusing on changing the rates, collection efforts in Buenos Aires could instead focus on reviewing the calculation formulas used to reassess property values each year, in order to create a structure that levies the corresponding tax at a specific frequency, instead of only doing so when ownership is transferred.

Figure 16: Property taxes: (a) rates, (b) collection (\% of income)

(a)

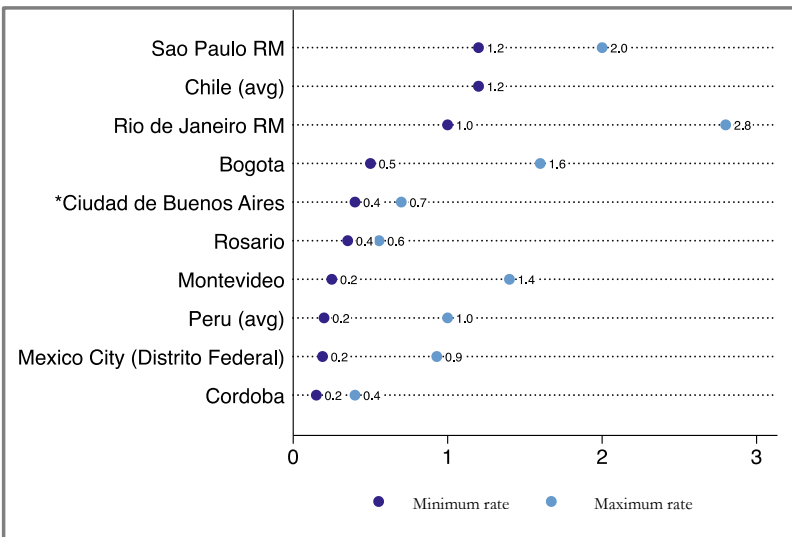

Source: Lincoln Institute (b)

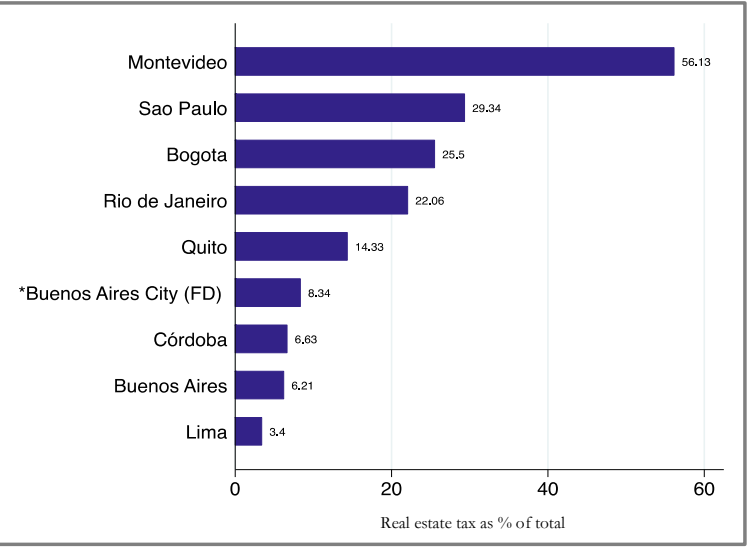

As for the high costs associated with strict national employment regulations, Buenos Aires can also pursue policy options that may help sectors with high export potential to mitigate their impact. One way to ease this constraint on strategic sectors is by promoting company-worker-union labor agreements at the company level that do not have extensive effects on the rest of the sector's workers and companies. Another alternative is to leverage on the city's already existing Economic District policy, and extend their current benefits - namely tax discounts, property subsidies, and access to talent - to also include special labor regimes. These Special Economic Zones (SEZs) with 
differentiated labor regimes could target service-sector companies with export potential, which naturally lend themselves to flexible and agile labor organization systems.

An interesting example of leveraging on SEZs as a means of easing constraints to the export sector are Panama's Ciudad del Saber [City of Knowledge] - aimed at promoting innovation as well as research and development activities - and Panama-Pacific, an industrial park (Hausmann, Obach, and Santos, 2016). In both cases, these SEZs have positively impacted the country's growth by relaxing barriers to export activity specific to Panama, such as the relative scarcity of talents (migratory policies), bureaucracy (infrastructure for paperwork), taxes (discounts on investment, special tax system), and employment regulations (special regime).

\section{Policies Aimed at Tackling Constraints}

Our approach to providing inputs for development policies builds on the assumption that a long list of sweeping structural reforms for overcoming binding constraints is impractical to governments, as these usually represent high administrative, political, and budgetary costs, and are slow to come about. For this reason, we propose a set of initiatives that can tackle or avoid the most relevant constraints to jump-starting Buenos Aires's export sector, while more significant reforms take place over time. In the previous section, we proposed a plan for prioritizing diversification opportunities according to different metrics of attractiveness and viability. Out of the five factors that represent the basic criteria for determining a sector's viability, two are directly related to the constraints: Ability to be organized around small and medium-sized businesses (employment regulations), and current exposure to the gross income tax (high tax burden). It follows, then, that the city can avoid said constraints by promoting sectors in which these have the least impact.

According to current legislation, companies with fewer than 100 workers are less exposed to different kinds of employment regulations. Based on this, we identified the frequency at which companies in each industrial code in the rest of the world are found to be organized around companies of fewer than 100 employees and, within this context, we have credited the "viability" of that activity in the prioritization exercise. The higher the likelihood that a sector can be organized around firms of less than 100 employees, the less exposed it will be to Argentina's stringent labor regulations.

A similar logic applies to the issue of gross income tax (IB). Since we found that the tax burden is one of the most important constraints, and recognizing that potential tax reforms may not be withing the feasible set of policies in the short term, we assigned a higher viability score to those industrial sectors exposed in the current legislation to lower rates of IB.

As detailed in section V.3, using the combination of viability and attractiveness metrics, we defined a preliminary sub-group of key industrial sectors that may be a priority among the city's strategies for productive development: specifically, some 59 activities in Phases 0 and 1. 
Phase 0 has 39 activities in which the city is already intensive and that boast a high degree of relative sophistication. The search for constraints on productivity and their possible solutions in this case can begin immediately, because valid partners in the city already exist. As for Phase 1, here we selected the 20 activities in which Buenos Aires does not currently display a Revealed Comparative Advantage, but which have the highest relative scores in both viability and attractiveness.

To organize the results and make it easier to visualize opportunities in Phase 0 and Phase 1, we regrouped them within seven export themes. ${ }^{18}$ The final result is shown in Figure 17, which presents the most general categories in the inner circle, and the broader themes that have at least one industry in Phases 0 and 1 in the outer circle.

The industries shown in the figure are the result of an intensive and iterative prioritization process, which managed to whittle down 213 industries and services in the intensive margin to just 39 and reduced 845 in the extensive margin to just 20 . Even so, in terms of the institutional capacity required to develop the productivity of the former and attract the latter, these numbers remain high.

In order to further distill this number into to an even more refined category of sectors, so as to optimize the focus of the government's resources in targeting them, the question remains as to which level of industry aggregation the authorities should focus their work on, in designing and implementing policy interventions. In looking for a practical answer to this question, we decided to select sections from Figure 17 that contain more than $10 \%$ of the diversification opportunities identified in Phases 0 and 1. The results are reported in Figure 18. When any of the more granular subsectors consist of more than $10 \%$ of the opportunities identified in Phases 0 and 1, we recommend working at the subsector level. Such is the case, for example, of Insurance and for Portfolio Management and Consulting (under Financial Services). In other cases, when none of the subsectors have more than $10 \%$ of the opportunities, but the category level in general does, we recommend working at the sector level. This is the case for IT Services and Business Services.

The sectors have been now prioritized and grouped into functional categories for public policy purposes, to facilitate the tackling of current constraints. At this level of analysis, authorities may choose to deploy institutional mechanisms in order to identify the specific challenges preventing their potential from materializing, and to mobilize private and public agents towards their mitigation or resolution. In order to carry out these functions, we suggest two institutional mechanisms, to be applied to themes and sectors already present (productivity task forces), and to those that belong to the extensive margin (investment promotion).

\footnotetext{
${ }^{18}$ In order to regroup them into broader categories, we moved from the four-digit industrial code at which the identification work was done, to the three-digit code. 
Figure 17: Share of areas and subareas in Phases 0 and 1

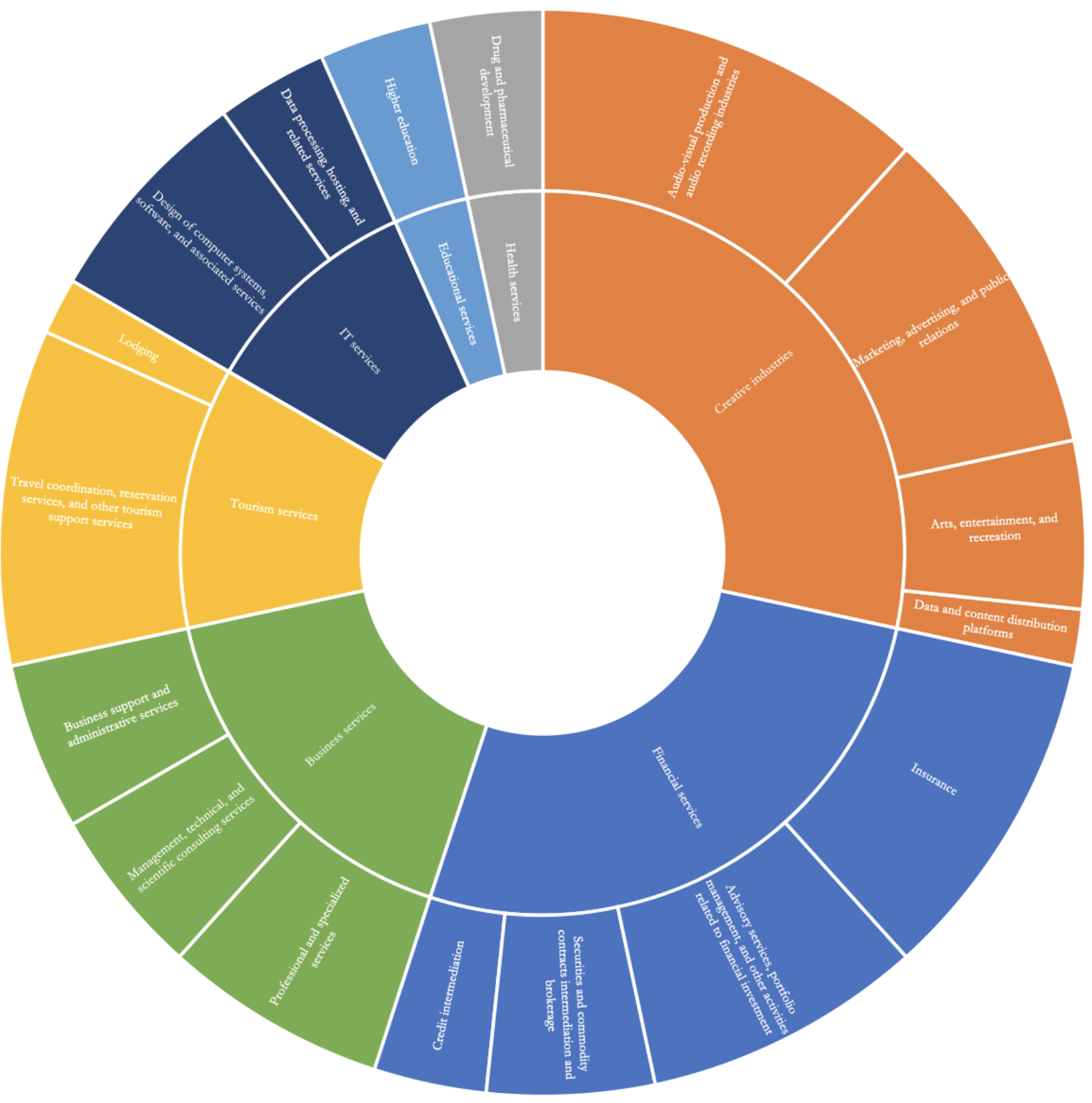

Source: Authors' chart.

Emerging Cities as Independent Engines of Growth: The Case of Buenos Aires 
Figure 18: Segments with more than 10\% of opportunities in Phases 0 and 1

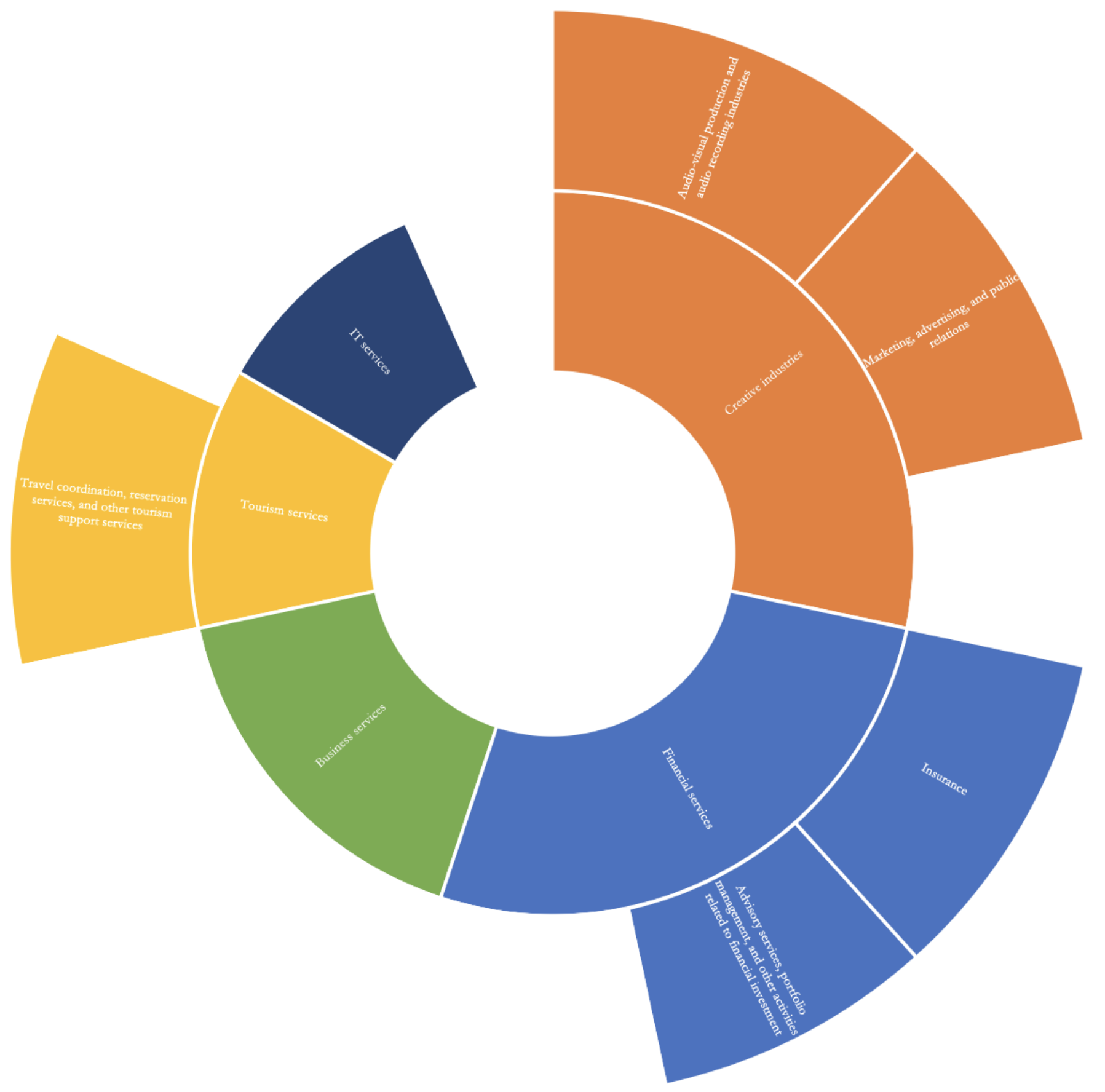

Source: Authors' chart. 


\section{Productivity Task Forces}

For sectors with export potential that already exist in the city (Phase 0), we suggest the creation of productivity taskforces as an institutional device for exploring interventions that may boost their development. These are simply temporary public-private working groups created around sectors to identify productivity constraints, propose collectively determined initiatives, define actions and those responsible for them, and monitor their implementation. The government's intervention and guidance in this process is essential in ensuring that the task force focuses on considerations involving the provision of public goods, avoidance of market failures, and resolving coordination issues, instead of market interventions aimed at protecting sectors (subsidies, tax discounts, tariff protection).

There are numerous examples of these kinds of institutional devices. Some relevant examples include mesas ejecutivas [executive committees] in Peru (Guezzi, 2016), and the Black Belt Teams (BBTs) in Sri Lanka (Andrews et al., 2017) and Albania. From a pool of well-documented experiences, we can obtain a set of basic principles that provide guidance to maximize the effectiveness of these task forces. In particular, there are specific lessons learned regarding the scale of the initiative, the nature of interaction, and the profile of the participants.

In terms of scale, we consider a modest, incremental approach to be the most advisable: begin with one or two task forces, learn from the experience, and adjust the design before extending it to a larger number of sectors. This is because the task tends to place additional pressures on the government's limited capacities, and it is not initially clear which types of interactions will tend to yield the best results. Thus, since only a limited number of sectors should be included when launching the initiative, we suggest publicly announcing the criteria for selecting these "pilot" sectors beforehand.

In terms of the goals for the interaction, it is important that all members of the task force support the initiative, and that they jointly regard its ultimate purpose to be the enhancement the sector's productivity - rather than just its bottom-line profitability.

With respect to task force participants, we propose assembling a team of industry leaders and relevant decision makers who are familiar with the sector's issues and have the convening authority, as well as government representatives who are sufficiently empowered to call upon different agencies from the public administration in implementing solutions to overcome bottlenecks and constraints on productivity. In addition, it can be beneficial to have academics with relevant expertise or independent sector experts that can lend impartial technical support to the conversation.

Having a good understanding of the city government's role in enhancing the productivity of certain sectors requires very specific skills that differ from traditional abilities found among other government responsibilities. Likewise, advancing initiatives from the private sector to deal with productive constraints tends to require knowledge that transcends its traditional range of experience. For this reason, we propose a process that may allow the government and task force participants to learn though a dynamic and participative approach, described in Figure 19. 
Figure 19: Description of the implementation process of productive task forces

\begin{tabular}{|c|c|c|c|c|c|}
\hline Select sectors & $\begin{array}{c}\text { Define } \\
\text { participants }\end{array}$ & $\begin{array}{c}\text { Identify } \\
\text { constraints }\end{array}$ & $\begin{array}{c}\text { Identify viable } \\
\text { solutions }\end{array}$ & Implement & $\begin{array}{l}\text { Evaluate and } \\
\text { adjust }\end{array}$ \\
\hline $\begin{array}{l}\text { - Strategic prioritization } \\
\text { - Supplementary } \\
\text { quantitative criteria } \\
\text { - Supplementary } \\
\text { qualitative criteria: } \\
\text { - Representative } \\
\text { counterparts in the } \\
\text { private sector } \\
\text { - Prior experience } \\
\text { - Institutional capacity } \\
\text { to manage } \\
\text { requirements }\end{array}$ & $\begin{array}{l}\text { - Sector } \\
\text { representatives: } \\
\text { Executives with } \\
\text { decision-making } \\
\text { power } \\
\text { - Government } \\
\text { representatives } \\
\text { with sector impact } \\
\text { - Organizing entity: } \\
\text { - Moderator } \\
\text { - Secretary } \\
\text { - Technical } \\
\text { assistants }\end{array}$ & $\begin{array}{l}\text { - Administrators } \\
\text { suggest initial set } \\
\text { of constraints } \\
\text { based on } \\
\text { research } \\
\text { - Task force } \\
\text { validates and } \\
\text { provides } \\
\text { constraints and } \\
\text { defines roots of } \\
\text { the problem } \\
\text { - Emphasis on } \\
\text { lacking public } \\
\text { goods or } \\
\text { coordination } \\
\text { failures } \\
\text { - Problems with } \\
\text { significant impact } \\
\text { on productivity } \\
\text { that do not require } \\
\text { large allocations } \\
\text { or long } \\
\text { implementation } \\
\text { periods } \\
\text { - The task force } \\
\text { must work on no } \\
\text { more than 2-3 } \\
\text { potential } \\
\text { constraints at a } \\
\text { time }\end{array}$ & $\begin{array}{l}\text { - Identify viable } \\
\text { solutions to } \\
\text { constraints } \\
\text { - Designate a sub- } \\
\text { team within the } \\
\text { task force for each } \\
\text { problem/constraint } \\
\text { - Sub-teams must } \\
\text { consist of all } \\
\text { relevant members } \\
\text { - They work on the } \\
\text { solution, are } \\
\text { responsible for } \\
\text { actions, and report } \\
\text { to the task force } \\
\text { monthly } \\
\text { - For recurring } \\
\text { themes (talent, } \\
\text { internationalization, } \\
\text { etc.), } \\
\text { multidisciplinary } \\
\text { subgroups can be } \\
\text { set up }\end{array}$ & $\begin{array}{l}\text { - Solutions are } \\
\text { implemented, and } \\
\text { results are } \\
\text { monitored } \\
\text { - Task force } \\
\text { monitors agreed } \\
\text { actions through } \\
\text { the different } \\
\text { government } \\
\text { entities involved at } \\
\text { city, metropolitan } \\
\text { area, and national } \\
\text { level }\end{array}$ & $\begin{array}{l}\text { - Results of the } \\
\text { action are } \\
\text { evaluated } \\
\text { - Experiment and } \\
\text { learn: Corrective } \\
\text { actions are } \\
\text { introduced, and } \\
\text { adjustments are } \\
\text { made based on } \\
\text { results } \\
\text { - This experimental } \\
\text { and iterative } \\
\text { approach is } \\
\text { critical to getting } \\
\text { at the roots of the } \\
\text { problems and } \\
\text { being able to offer } \\
\text { solutions and } \\
\text { create } \\
\text { momentum } \\
\text { through sustained } \\
\text { progress }\end{array}$ \\
\hline
\end{tabular}

Source: Authors' chart.

The selection of sectors through the methodology we have proposed, and the common elements that run throughout the successful Peruvian, Sri Lankan and Albanian task force initiatives we described earlier, constitute the first two steps (Select sectors and Define participants) of the implementation process. The third step (Identify constraints) requires advance work by the entity promoting the initiative, to be carried out by a team of researchers. This advance work must inform the task force's promotional team about possible constraints and serve as a starting point for discussions among participants. The binding constraints that were identified in the Growth Diagnostic - tax burden and employment regulations - may also apply at the sector level, but it is also quite possible that different constraints that were not detected at the general level are binding for a particular sector being considered. Task force members should validate these additional sector-specific constraints and then proceed to identify their root causes. Issues discussed in the task force should have a large enough scope so that resolving them would significantly impact productivity, but not so large that they require significant resource allocations or long implementation periods.

The fourth step of the process involves identifying viable solutions to the relevant sector constraints, and the ensuing appointment of multidisciplinary task force sub-groups in charged with developing and implementing them. At each meeting, task force sub-groups should report on progress made in the design of interventions, as well as on the actors required for their effective 
implementation, which may include individuals with a certain degree of technical specialization. In the case of Buenos Aires, the city should be prepared to assemble units dedicated to resolving bottlenecks in areas as diverse as availability of talent, internationalization of local businesses, access to finance, the provision of public goods, and regulation reform.

The next step in the productivity task force process requires that the different private actors and government entities involved follow up on the implementation of the agreed-upon actions. This final step should culminate in an "evaluate and adjust" phase, whereby specific results derived from the actions are assessed, corrective measures are introduced, and improvements are made in terms of the preliminary results.

\section{Investment Promotion}

As a second institutional mechanism aimed at fully realizing sector-specific development potential, we suggest reinforcing the capacities of Buenos Aires's investment promotion agency. In some ways, the process is similar to that of productive task forces, with one very significant difference: It involves identifying and understanding constraints on the competitiveness of sectors that are not yet present in city, or that are present at a very low intensity (Phase 1). Thus, it is an essential tool for obtaining information, which complements the productive agenda derived from interacting with firms that are already part of the city's industrial pool. Together, these institutional set-ups serve as informationrevelation mechanisms that can help identify additional relevant constraints that can't be directly gleaned through independent analytical work.

In guiding productive development policies for extensive margin sectors in Buenos Aires, the city's investment promotion agency faces a challenge that productive task forces do not. It must act proactively and go through the steps of identifying constraints and suggesting viable solutions without the immediate support and feedback of the parties involved. The abilities needed to diagnose the city's industry and competitive profile are similar to the ones employed by productive task forces, but the mechanisms for validating results are more sporadic and less systematic - for example, through direct interviews with the target companies identified at the global or regional level.

As with the productive task forces, the key is creating a process whereby the party responsible for promoting investment is able to incrementally learn and adjust, based on the information gathered in interactions with potential investors, entrepreneurs and other relevant stakeholders in industries that display greater potential. Once constraints have been confirmed and identified, and viable solutions have been preliminary designed, the next step is disclosure, which may take various forms. One such form is to create industry pitchbooks that summarize the main advantages of carrying out the specific economic activity in Buenos Aires, focusing on the factors, public goods, and inputs in which these industries are most intensive. Another form could be participating in specialized international investment trade fairs. In our experience, the latter, even though useful for establishing new contacts 
and canvassing the policy space in alternative destinations, tend to contribute less qualitative information related to persistent potential constraints.

Within this process, the meaningful and proactive engagement of the investment promotion agency with potential investors is crucial. Once initial interest has been detected and preliminary steps have been taken to consider launching operations in the city, continued feedback and constant followingup should be deployed in the interest of attracting the investment. While this might seem obvious, in our experience, it is this critical phase of supporting companies that have answered the call of the investment promotion agency that usually tends to fall into "no man's land," resulting in many lost opportunities and wasted efforts.

Ultimately, the challenges that a location faces in learning to make new products and services are not that different from the obstacles that governments face in developing activities and institutional mechanisms to increase companies' productivity, boost exports, or attract new investments. The experimental approach that we have suggested is based on a learning-by-doing perspective; a prototyping process that makes it possible to accomplish goals on a small scale, evaluate results, correct mistakes, and achieve eventual and sustained progress. 


\section{References}

Andrews, M., Ariyasinghe, D., Batuwanthudawa, T., Darmasiri, S., de Silva. N., Harrington, P., Jayasinghe, P., et al. (2017). "Learning to Target for Economic Diversification: PDIA in Sri Lanka".

Crespi G., Fernández-Arias E., Stein E. (2014). "A Conceptual Framework for Productive Development Policies.” In: Crespi G., Fernández-Arias E., Stein E. (eds.), Rethinking Productive Development. Palgrave Macmillan, New York.

Collier, P. (2018). “The future of capitalism: Facing the new anxieties”. Harper Collins, New York.

Galiani, S. y Serramo, M, (2019), "Why the Total tax and Contribution rate of Doing Business is a flawed measure of the tax burden". Vox Lacea

Ghezzi, P. (2016). "Mesas ejecutivas: A new tool for productive diversification". Ministerio de la Producción del Perú.

Hausmann, R., Hidalgo, C., Bustos, S., Coscia, M., Chung, S., Jimenez J., Simoes, A., y Yildirim, M. (2011). "The Atlas of Economic Complexity”. Puritan Press, Cambridge, MA.

Hausmann, R., y Klinger, B. (2006), "Structural Transformation and Patterns of Comparative Advantage." CID Working Paper No 128.

Hausmann, R., Obach, J. and Santos, M.A. (2017). Special Economic Zones in Panama: Technology Spillovers from a Labor Market Perspective. Harvard Center for International Development, Faculty Working Paper Series No. 326, October 2016 (revised in May 2017).

Hausmann, R., Rodrik, D., y Sabel, C. (2008). "Reconfiguring Industrial Policy: A Framework with an Application to South Africa". Copy at http://j.mp/2oEgDmn.

Hausmann, R., Velasco, A. y Rodrik, D. (2005) “Growth Diagnostics". En J. E. Stiglitz y N. Seroa (eds), The Washington Consensus Reconsidered: Towards a New Global Governance. Oxford University Press, Oxford. 


\section{ANNEX I: Attachments}

\section{Distribution of Exports in Sectors in which Buenos Aires is Intensive (2016)}

Figure 20: Distribution of exports in sectors in which Buenos Aires is intensive (2016), Buenos Aires and international peers

Tourism
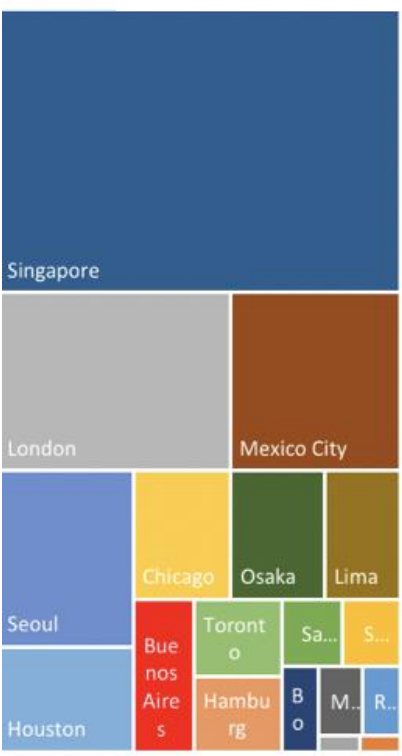

Vehicles

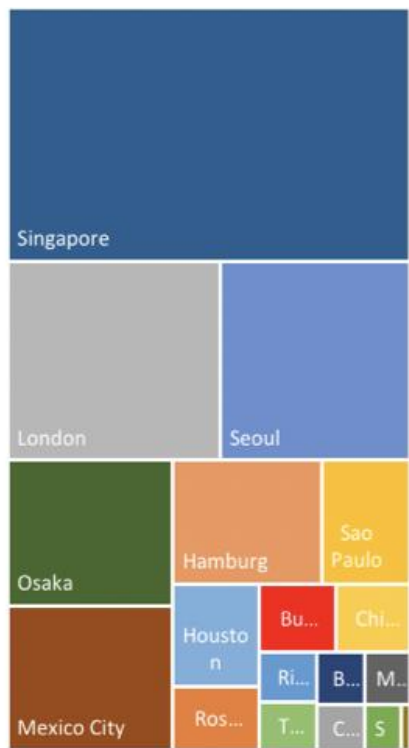

Chemicals and plastics

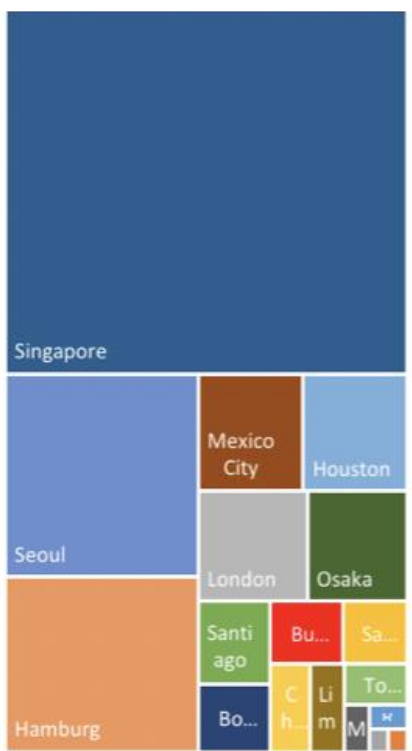

Business services

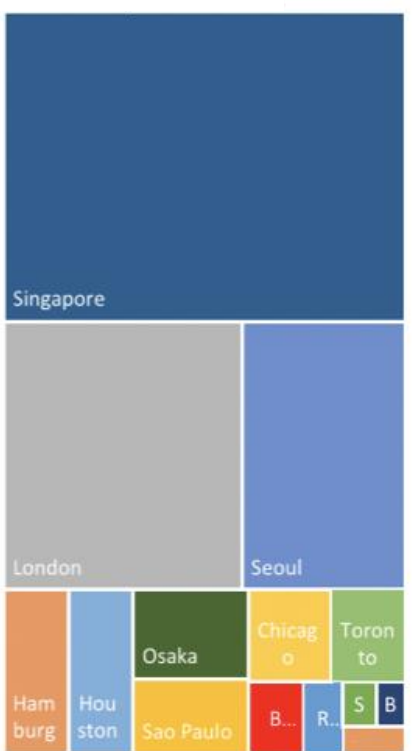

Source: Authors' estimates based on UN Comtrade, IMF, and Dun \& Bradstreet. 


\section{Thematic Areas, Thematic Subareas, and Industries}

\begin{tabular}{|c|c|c|c|}
\hline Thematic Area & Thematic Subarea & $\begin{array}{l}\text { Examples of specific activities in which } \\
\text { the city shows RCAs and is able to grow } \\
\text { within the intensive margin }\end{array}$ & $\begin{array}{l}\text { Examples of specific activities that the } \\
\text { city can develop more intensively to } \\
\text { increase the extensive margin }\end{array}$ \\
\hline Business services & $\begin{array}{l}\text { Professional and } \\
\text { specialized services }\end{array}$ & $\begin{array}{l}\text { - Engineering services } \\
\text { - Other accounting services } \\
\text { - Law firms }\end{array}$ & $\begin{array}{l}\text { - Interior design services } \\
\text { - Specialized legal services } \\
\text { - Architectural services } \\
\text { - Certified public accountant offices } \\
\text { - Translation and interpreting services }\end{array}$ \\
\hline Business services & $\begin{array}{l}\text { Business support and } \\
\text { administrative services }\end{array}$ & $\begin{array}{l}\text { - Security system services } \\
\text { (except locksmiths) }\end{array}$ & $\begin{array}{l}\text { - Court reporting and } \\
\text { stenographer services } \\
\text { - Executive recruiting services } \\
\text { - Office administrative services } \\
\text { - Documentation services }\end{array}$ \\
\hline Business services & $\begin{array}{l}\text { Management, } \\
\text { technical, and scientific } \\
\text { consulting services }\end{array}$ & $\begin{array}{l}\text { - Other scientific and technical } \\
\text { consulting services } \\
\text { - Management consulting services }\end{array}$ & $\begin{array}{l}\text { - Other management consulting services } \\
\text { - Human resources consulting services }\end{array}$ \\
\hline Financial services & Insurance & $\begin{array}{l}\text { - All other insurance activities } \\
\text { - Property and accident insurance (Direct) } \\
\text { - Life insurance (Direct) } \\
\text { - Reinsurance }\end{array}$ & $\begin{array}{l}\text { - Claims adjusting } \\
\text { - Insurance agencies and brokers }\end{array}$ \\
\hline Financial services & $\begin{array}{l}\text { Advisory services, } \\
\text { portfolio management, } \\
\text { and other activities } \\
\text { related to financial } \\
\text { investment }\end{array}$ & $\begin{array}{l}\text { - Health and welfare funds } \\
\text { - Other insurance funds }\end{array}$ & $\begin{array}{l}\text { - Pension funds } \\
\text { - Investment advice } \\
\text { - Open-ended mutual funds } \\
\text { - Portfolio management } \\
\text { - Other financial vehicles } \\
\text { - Miscellaneous financial } \\
\text { intermediation services } \\
\text { - Trust and custodial activities } \\
\text { - Miscellaneous financial } \\
\text { investment activities }\end{array}$ \\
\hline Financial services & $\begin{array}{l}\text { Securities and } \\
\text { commodity contracts } \\
\text { intermediation and } \\
\text { brokerage }\end{array}$ & $\begin{array}{l}\text { - Commodity exchanges and call options } \\
\text { - Securities brokers }\end{array}$ & $\begin{array}{l}\text { - Investment banking and securities trading } \\
\text { - Negotiation of commodity contracts }\end{array}$ \\
\hline Financial services & Credit intermediation & & $\begin{array}{l}\text { - Credit card issuance } \\
\text { - Real estate loans } \\
\text { - Commercial banks } \\
\text { - Credit unions } \\
\text { - Savings institutions } \\
\text { - Processing financial transactions, } \\
\text { reserves, and information exchange } \\
\text { activities }\end{array}$ \\
\hline
\end{tabular}




\begin{tabular}{|c|c|c|c|}
\hline Thematic Area & Thematic Subarea & $\begin{array}{c}\text { Examples of specific activities in } \\
\text { which the city shows RCAs and is able to } \\
\text { grow within the intensive margin }\end{array}$ & $\begin{array}{l}\text { Examples of specific activities that the } \\
\text { city can develop more intensively to } \\
\text { increase the extensive margin }\end{array}$ \\
\hline Health services & $\begin{array}{l}\text { Development of drugs } \\
\text { and pharmaceuticals }\end{array}$ & $\begin{array}{l}\text { - Manufacture of } \\
\text { pharmaceutical preparations } \\
\text { - Medicinal and herbal manufacturing }\end{array}$ & \\
\hline Health services & $\begin{array}{l}\text { Hospitals and other } \\
\text { specialist care facilities }\end{array}$ & & $\begin{array}{l}\text { - Other residential care facilities } \\
\text { - Residential mental health and } \\
\text { substance abuse facilities } \\
\text { - Psychiatric and substance abuse hospitals } \\
\text { - Nursing care facilities }\end{array}$ \\
\hline Health services & $\begin{array}{l}\text { Outpatient healthcare } \\
\text { and health services }\end{array}$ & & $\begin{array}{l}\text { - Podiatry offices } \\
\text { - Outpatient mental health and } \\
\text { substance abuse centers } \\
\text { - Other diverse outpatient health services } \\
\text { - Offices of mental health } \\
\text { practitioners (except physicians) } \\
\text { - All other healthcare centers }\end{array}$ \\
\hline Tourism services & Lodging & & $\begin{array}{l}\text { - Bed-and-Breakfast Inns/Posadas } \\
\text { - Temporary housing, lodges, } \\
\text { dormitories, and camps }\end{array}$ \\
\hline Tourism services & $\begin{array}{l}\text { Travel arrangements, } \\
\text { reservation services, } \\
\text { and other tourism } \\
\text { support services }\end{array}$ & $\begin{array}{l}\text { - Deep sea passenger transportation } \\
\text { - Limousine services } \\
\text { - Travel agencies }\end{array}$ & $\begin{array}{l}\text { - Tour operators } \\
\text { - Convention and visitors bureaus } \\
\text { - Other travel arrangement } \\
\text { services and reservation services }\end{array}$ \\
\hline Tourism services & $\begin{array}{l}\text { Restaurants and other } \\
\text { food services }\end{array}$ & & $\begin{array}{l}\text { - Cafeterias, grills, and buffets } \\
\text { - Full-service restaurants }\end{array}$ \\
\hline Creative industries & $\begin{array}{l}\text { Arts, entertainment, } \\
\text { and recreation }\end{array}$ & $\begin{array}{l}\text { - Other performing arts companies } \\
\text { - Agents \& managers for } \\
\text { performers, athletes, artists, public figures } \\
\text { - Promoters of performing arts, } \\
\text { sports, and similar events } \\
\text { (without facilities) }\end{array}$ & $\begin{array}{l}\text { - Musical groups and artists } \\
\text { - Dance companies } \\
\text { - Independent artists, writers, performers } \\
\text { - Museums }\end{array}$ \\
\hline Creative industries & $\begin{array}{l}\text { Marketing, advertising, } \\
\text { and public relations }\end{array}$ & $\begin{array}{l}\text { - Market research and public } \\
\text { opinion surveys } \\
\text { - Media representatives } \\
\text { - Advertising agencies } \\
\text { - Public relations agencies }\end{array}$ & - Ad-buy agencies \\
\hline Creative industries & $\begin{array}{l}\text { Data and content } \\
\text { distribution platforms }\end{array}$ & - Syndicated news & $\begin{array}{l}\text { - Radio stations } \\
\text { - Cable companies and other } \\
\text { subscription programming }\end{array}$ \\
\hline Creative industries & $\begin{array}{l}\text { Audiovisual } \\
\text { production and sound- } \\
\text { recording industries }\end{array}$ & $\begin{array}{l}\text { - Film and video distribution } \\
\text { - Music publishers } \\
\text { - Other sound recording industries }\end{array}$ & $\begin{array}{l}\text { - Sound recording studios } \\
\text { - Sound recording distribution } \\
\text { and production } \\
\text { - Television production and } \\
\text { other postproduction services } \\
\text { - Other movie and video industries }\end{array}$ \\
\hline IT services & $\begin{array}{l}\text { Design of computer } \\
\text { systems, software, and } \\
\text { associated services }\end{array}$ & $\begin{array}{l}\text { - Computer installations } \\
\text { management services } \\
\text { - Software publication and reproduction } \\
\text { - Custom programming services }\end{array}$ & - Digital system design services \\
\hline IT services & $\begin{array}{l}\text { Data processing, } \\
\text { hosting, and related } \\
\text { services }\end{array}$ & - Data processing, hosting, and service & $\begin{array}{l}\text { - Publication and dissemination } \\
\text { on the internet and web search portals }\end{array}$ \\
\hline
\end{tabular}




\begin{tabular}{|l|l|l|l|}
\hline Thematic Area & Thematic Subarea & $\begin{array}{c}\text { Examples of specific activities in } \\
\text { which the city shows RCAs and is able to } \\
\text { grow within the intensive margin }\end{array}$ & $\begin{array}{c}\text { Examples of specific activities that the } \\
\text { city can develop more intensively to } \\
\text { increase the extensive margin }\end{array}$ \\
\hline Education services & Higher education & $\begin{array}{l}\text { - Colleges of Fine Arts } \\
\text { - Language schools }\end{array}$ & - Higher education institutions \\
\hline Education services & $\begin{array}{l}\text { Research and } \\
\text { development }\end{array}$ & & $\begin{array}{l}\text { - Research and Development in } \\
\text { Social Sciences and Humanities } \\
\text { - Research and Development in } \\
\text { Physical Engineering, Engineering, } \\
\text { Biological Sciences }\end{array}$ \\
\hline Education services & $\begin{array}{l}\text { Education support } \\
\text { services }\end{array}$ & & $\begin{array}{l}\text { - Preparation for exams and tutoring } \\
\text { - Education support services }\end{array}$ \\
\hline & $\begin{array}{l}\text { Supplementary, } \\
\text { professional, and/or } \\
\text { specialized training } \\
\text { services }\end{array}$ & & $\begin{array}{l}\text { - Cosmetology, hairdressing, and } \\
\text { barber schools } \\
\text { - All other schools and means } \\
\text { of instruction }\end{array}$ \\
\hline
\end{tabular}




\section{Description of Thematic Areas and Subareas}

\begin{tabular}{|c|c|c|c|}
\hline Thematic Area & Thematic Subarea & General Description & $\begin{array}{l}\text { Examples of Companies } \\
\text { in the Thematic Subarea }\end{array}$ \\
\hline Business services & \begin{tabular}{|l} 
Professional and \\
specialized services
\end{tabular} & $\begin{array}{l}\text { These firms offer the knowledge and abilities of their employees, } \\
\text { often by assignment, where an individual or team is responsible for } \\
\text { providing services to the client. The individual industries in this } \\
\text { subsector are defined on the basis of the service provider's specific } \\
\text { experience and training. The firms classified in this subsector are } \\
\text { selling specialized expertise, such as engineering, accounting, } \\
\text { architecture, interior design, and translation services. Much of the } \\
\text { experience requires degrees, although not in every case. }\end{array}$ & $\begin{array}{l}\text { - Rockwell Collins Inc } \\
\text { - Deloitte } \\
\text { Consulting LLP } \\
\text {-Pricewaterhouse- } \\
\text { Coopers LLP } \\
\text { - Seagate Technology, } \\
\text { LLC }\end{array}$ \\
\hline Business services & $\begin{array}{l}\text { Business support and } \\
\text { administrative services }\end{array}$ & $\begin{array}{l}\text { This industry group comprises firms primarily engaged in providing } \\
\text { business support services, such as preparing documents, operating call } \\
\text { centers, managing security systems, operating business service } \\
\text { centers, recruiting executives with specialized profiles, collecting } \\
\text { outstanding payment claims, and providing credit information. }\end{array}$ & $\begin{array}{l}\text { - Eli Lilly and Company } \\
\text { - Hudson's Bay } \\
\text { Company } \\
\text { - Brink's Company }\end{array}$ \\
\hline Business services & $\begin{array}{l}\text { Management, technical } \\
\text { and scientific } \\
\text { consulting services }\end{array}$ & $\begin{array}{l}\text { This industry group comprises firms primarily engaged in providing } \\
\text { advisory services and support to companies and other organizations } \\
\text { in management, and in environmental, human resources, scientific, } \\
\text { and technical matters. }\end{array}$ & $\begin{array}{l}\text { - Rockwell Automation } \\
\text { Inc } \\
\text { - Avaya Inc } \\
\text { - Booz Allen Hamilton } \\
\text { - McKinsey \& Co }\end{array}$ \\
\hline Financial services & Insurance & $\begin{array}{l}\text { Firms that act as agents (brokers) in selling annuities and insurance } \\
\text { policies or that provide other employee benefits and insurance-related } \\
\text { services, such as claims adjustment and third-party administration. }\end{array}$ & $\begin{array}{l}\text { - Engle Martin and } \\
\text { Associate Inc } \\
\text { - CVS Health Corp } \\
\text { - John Hancock } \\
\text { Financial Services Inc } \\
\text { - AMERISAFE Inc }\end{array}$ \\
\hline Financial services & $\begin{array}{l}\text { Advisory services, } \\
\text { portfolio management, } \\
\text { and other activities } \\
\text { related to financial } \\
\text { investment }\end{array}$ & $\begin{array}{l}\text { Legal entities (investment funds and/or funds) organized to pool } \\
\text { securities or other assets (except employee benefits and insurance } \\
\text { funds) on behalf of beneficiaries or shareholders in stock companies } \\
\text { or mutual funds. }\end{array}$ & $\begin{array}{l}\text { - T. Rowe Price } \\
\text { - Fidelity Investments }\end{array}$ \\
\hline Financial services & $\begin{array}{l}\text { Securities and } \\
\text { commodity contracts } \\
\text { intermediation and } \\
\text { brokerage }\end{array}$ & $\begin{array}{l}\text { This industrial group comprises firms primarily engaged in placing } \\
\text { venture capital in the process of subscribing issues of securities or in } \\
\text { creating markets for securities and commodities and those acting as } \\
\text { agents and/or brokers between buyers and sellers of securities and } \\
\text { commodities, generally on a commission basis. }\end{array}$ & $\begin{array}{l}\text { - Credit Suisse USA Inc } \\
\text { - Rosenthal Collins } \\
\text { Group } \\
\text { - NSX Holdings Inc } \\
\text { - Bloomberg LP }\end{array}$ \\
\hline Financial services & Credit intermediation & $\begin{array}{l}\text { Comprises firms primarily engaged in facilitating credit intermediation } \\
\text { by conducting activities such as organizing loans by connecting } \\
\text { lenders and borrowers and clearing checks and transactions by credit } \\
\text { card. }\end{array}$ & $\begin{array}{l}\text { - Bank of America } \\
\text { - University of Iowa } \\
\text { Community Credit } \\
\text { Union } \\
\text { - American Express }\end{array}$ \\
\hline
\end{tabular}




\begin{tabular}{|c|c|c|c|}
\hline Thematic Area & Thematic Subarea & General Description & $\begin{array}{l}\text { Examples of Companies } \\
\text { in the Thematic Subarea }\end{array}$ \\
\hline Health services & $\begin{array}{l}\text { Development of drugs } \\
\text { and pharmaceuticals }\end{array}$ & $\begin{array}{l}\text { Firms primarily engaged in manufacturing drugs and related products } \\
\text { for human or animal use. }\end{array}$ & $\begin{array}{l}\text { - Amgen Inc } \\
\text { - Johnson And Johnson } \\
\text { - Mitsubishi } \\
\text { Chemical USA }\end{array}$ \\
\hline Health services & $\begin{array}{l}\text { Hospitals and other } \\
\text { specialist care facilities }\end{array}$ & $\begin{array}{l}\text { Comprises establishments that provide medical and social welfare to } \\
\text { individuals. This sector includes healthcare and social services. The } \\
\text { industries in this sector are set out on a continuum, beginning with } \\
\text { firms that exclusively provide healthcare, continuing with those that } \\
\text { provide healthcare and social services, and ending with those that only } \\
\text { provide social services. Trained professionals provide the services } \\
\text { offered by establishments. }\end{array}$ & $\begin{array}{l}\text { - Athena Health Care } \\
\text { Systems } \\
\text { - Woodridge Behavioral } \\
\text { Care } \\
\text { - Sunrise Senior } \\
\text { Living Inc } \\
\text { - University of Kansas } \\
\text { Hospital } \\
\text { - Denver Health }\end{array}$ \\
\hline Health services & $\begin{array}{l}\text { Outpatient healthcare } \\
\text { and medical services }\end{array}$ & $\begin{array}{l}\text { Includes establishments of independent healthcare professionals } \\
\text { (except general physicians and dentists) }\end{array}$ & $\begin{array}{l}\text { - Orlando Foot and } \\
\text { Ankle Clinic } \\
\text { - Mid America } \\
\text { Psychological and } \\
\text { Counseling Services } \\
\text { - U.S. Physical Therapy } \\
\text { Inc } \\
\text { - Alliance Care }\end{array}$ \\
\hline Tourism services & Lodging & $\begin{array}{l}\text { Includes establishments offering short-stay accommodation (e.g., } \\
\text { hotels, B\&Bs, inns) as well as those offering longer-term temporary } \\
\text { accommodation that, during the occupancy period, may serve as a } \\
\text { principal residence. These establishments may also offer } \\
\text { supplementary services, such as cleaning, food, and laundry services. }\end{array}$ & $\begin{array}{l}\text { - Hawthorne Hotel } \\
\text { - Wynn Resorts Limited } \\
\text { - Marriott }\end{array}$ \\
\hline Tourism services & $\begin{array}{l}\text { Travel arrangements, } \\
\text { reservation services, } \\
\text { and other tourism } \\
\text { support services }\end{array}$ & $\begin{array}{l}\text { Includes travel agents, tour operators, and providers of other travel } \\
\text { organization services, such as hotel reservations and restaurants and } \\
\text { ticketing, dealing with many kinds of customers including individual } \\
\text { consumers. Also includes specialized passenger transportation } \\
\text { services, including private chauffeurs and water transport. }\end{array}$ & $\begin{array}{l}\text { - Historic Tours } \\
\text { of America Inc } \\
\text { - Maverick } \\
\text { Helicopter Tours } \\
\text { - Virgin Holidays } \\
\text { - Greater Houston } \\
\text { Convention and } \\
\text { Visitors Bureau }\end{array}$ \\
\hline Tourism services & $\begin{array}{l}\text { Restaurants and other } \\
\text { food services }\end{array}$ & $\begin{array}{l}\text { Establishments primarily engaged in providing food service to } \\
\text { customers who order and receive the service while seated and who } \\
\text { pay after eating or else who order and select items from a counter, a } \\
\text { food bar, or cafeteria line (or order by phone) and who pay before } \\
\text { eating. }\end{array}$ & $\begin{array}{l}\text { - McDonald's Corp } \\
\text { - Taco Bell Corporate } \\
\text { Office }\end{array}$ \\
\hline Creative industries & $\begin{array}{l}\text { Arts, entertainment, } \\
\text { and recreation }\end{array}$ & $\begin{array}{l}\text { Includes a wide range of establishments operating facilities or } \\
\text { providing services to satisfy diverse cultural, entertainment, and } \\
\text { recreational interests. Significant among these are sports activities, } \\
\text { performing arts, and other cultural activities. }\end{array}$ & $\begin{array}{l}\text { - New York City } \\
\text { Ballet Inc. } \\
\text { - Kroenke Sports } \\
\text { and Entertainment } \\
\text { - United Talent } \\
\text { Agency Inc } \\
\text { - Chicago Cubs }\end{array}$ \\
\hline Creative industries & $\begin{array}{l}\text { Marketing, advertising, } \\
\text { and public relations }\end{array}$ & $\begin{array}{l}\text { Comprises establishments primarily engaged in creating } \\
\text { communications strategies and advertising campaigns and getting that } \\
\text { advertising into periodicals, magazines, radio, television, and other } \\
\text { media outlets. Also includes establishments that conduct surveys, } \\
\text { market research activities, as well as public relations agencies. }\end{array}$ & $\begin{array}{l}\text { - Elite SEM } \\
\text { - NPD Group Inc } \\
\text { - National } \\
\text { Research Corp } \\
\text { - Groupon Inc } \\
\text { - Tribune Publishing Co }\end{array}$ \\
\hline
\end{tabular}




\begin{tabular}{|c|c|c|c|}
\hline Thematic Area & Thematic Subarea & General Description & $\begin{array}{l}\text { Examples of Companies } \\
\text { in the Thematic Subarea }\end{array}$ \\
\hline Creative industries & $\begin{array}{l}\text { Data and content } \\
\text { dissemination } \\
\text { platforms }\end{array}$ & $\begin{array}{l}\text { Includes broadcasting companies (except internet-based) that create } \\
\text { content or acquire the rights to distribute and, subsequently, } \\
\text { broadcast content. Also in this category are companies that operate } \\
\text { broadcasting studios and installations for broadcasting, over the air or } \\
\text { by satellite, radio and television entertainment programs, news, } \\
\text { interviews, etc., as well as companies operating studios and facilities } \\
\text { for broadcasting programs normally of restricted dissemination } \\
\text { (limited format, such as youth-oriented news, sports, education, and } \\
\text { programming) provided on a subscription or rate basis. }\end{array}$ & $\begin{array}{l}\text { - Dish Network, LLC } \\
\text { - AMC Networks Inc } \\
\text { - Agence France Presse } \\
\text { - Golf Channel Inc } \\
\text { - Reuters America }\end{array}$ \\
\hline Creative industries & $\begin{array}{l}\text { Audiovisual production } \\
\text { and sound recording } \\
\text { industries }\end{array}$ & $\begin{array}{l}\text { Companies primarily engaged in the production and/or distribution } \\
\text { of films, videos, television programs or commercials, musical } \\
\text { compositions, and other sound recordings, in showing movies, or } \\
\text { providing postproduction and similar services. }\end{array}$ & $\begin{array}{l}\text { - Bmg Rights } \\
\text { Management } \\
\text { - Sony } \\
\text { Music Entertainment } \\
\text { - Walt Disney } \\
\text { Imagineering } \\
\text { - Universal } \\
\text { Studios Company } \\
\end{array}$ \\
\hline IT services & $\begin{array}{l}\text { Design of computer } \\
\text { systems, software, and } \\
\text { associated services }\end{array}$ & $\begin{array}{l}\text { The main components of this sector are the software development } \\
\text { and publishing industries, both for mass and personal consumption. }\end{array}$ & $\begin{array}{l}\text { - SAP America Inc. } \\
\text { - Apple Inc } \\
\text { - Oracle Corp. } \\
\text { - Belkin International } \\
\text { Inc }\end{array}$ \\
\hline IT services & $\begin{array}{l}\text { Data processing, } \\
\text { hosting, and related } \\
\text { services }\end{array}$ & $\begin{array}{l}\text { Companies that provide infrastructure for data processing and/or } \\
\text { hosting services. Also includes companies engaged in publishing } \\
\text { and/or broadcasting content exclusively on the internet or operating } \\
\text { websites using a search engine to create and maintain vast databases } \\
\text { of addresses and internet content in an easy-to-access format. }\end{array}$ & $\begin{array}{l}\text { - Facebook } \\
\text { - Netflix } \\
\text { - Twitter } \\
\text { - Baidu }\end{array}$ \\
\hline Educational services & Higher education & $\begin{array}{l}\text { The industries in the Educational Services subsector provide } \\
\text { instruction and training in a wide variety of highly specialized subjects. } \\
\text { The instruction and training are provided by specialized companies, } \\
\text { such as schools, institutes, universities, and training centers. }\end{array}$ & $\begin{array}{l}\text { - Berlitz } \\
\text { - EF } \\
\text { - Fred Astaire } \\
\text { Dance Studios Inc }\end{array}$ \\
\hline Educational services & $\begin{array}{l}\text { Research and } \\
\text { development }\end{array}$ & $\begin{array}{l}\text { Comprises companies engaged in systematically conducting original } \\
\text { research to obtain new knowledge (research) and/or applying the } \\
\text { results of research or other scientific knowledge to create new or } \\
\text { significantly improved products or processes (experimental } \\
\text { development). The industries in this industrial group are defined } \\
\text { based on the research domain, meaning the company's scientific } \\
\text { experience. }\end{array}$ & - GlaxoSmithKline Inc \\
\hline Educational services & $\begin{array}{l}\text { Education support } \\
\text { services }\end{array}$ & $\begin{array}{l}\text { This industry comprises companies primarily engaged in providing } \\
\text { services that support educational systems or processes as well as the } \\
\text { institutions that offer tutoring and services that assist with exam } \\
\text { preparation. }\end{array}$ & - Pearson Education \\
\hline Educational services & $\begin{array}{l}\text { Continuing, } \\
\text { professional, and/or } \\
\text { specialist education }\end{array}$ & $\begin{array}{l}\text { Includes companies primarily engaged in one of the following fields, } \\
\text { able to provide training through educational platforms that allow } \\
\text { students to attend the class online: (1) offering classes on basic } \\
\text { business skills or professional support and possibly offering classes in } \\
\text { basic office skills, such as word processing; (2) conducting computer } \\
\text { training (except computer repairs); (3) offering a variety of short } \\
\text { classes on management and professional development. }\end{array}$ & $\begin{array}{l}\text { - Plymouth College } \\
\text { of Beauty } \\
\text { - Universal } \\
\text { Technical Institute Inc }\end{array}$ \\
\hline
\end{tabular}




\section{Methodology for Estimating Missing Occupations and Inputs}

A crucial element in developing any productive activity is the ability to access the required intermediate inputs and skills/occupations. Required intermediate inputs can be considered to be the broad set of goods and services that a company participating in an industry usually demands from third parties. Required occupations, meanwhile, are those occupations that are generally employed to carry out the activity. The ability to access these inputs and occupations at a location is essential to determine the viability of the industry there.

Due to their relevance, the Center for International Development (CID) developed a methodology for the purposes of this research initiative, to approximate the accessibility these factors, which is based on information from the Input-Output Table and U.S. Bureau of Labor Statistics. As indicated in the report, we used U.S. data is because of the high degree of accessibility and reliability of its databases. It also displays an advanced productive structure and a wide range of industries, which is why it could provide a good approximation for how industries interact and what type of skills these will require once they are fully developed in Buenos Aires.

First, the methodology tries to identify which inputs and occupations are intensively required by the industries in question. To this end, an RCA is calculated in the use of different inputs and occupations per industry. This indicator is similar to that used to measure the intensity at which an industry operates in the city (as previously explained). Inputs are calculated as follows: the percentage of total demands for inputs for a specific industry for a particular input is divided by the percentage of total demand for inputs in the economy resulting for that same input. Occupations are estimated as follows: the percentage of the total employees in a specific industry concentrated in a particular occupation is divided by the percentage of all employees in the economy that are concentrated in that occupation. In both cases, if the RCA is equal to or greater than 1, the methodology determines that that input, or occupation is intensively demanded by the industry in question.

Subsequently, to assess whether the inputs and occupations intensively required by diversification opportunities are available in the city, we used an indirect method. Specifically, this method consists of assessing whether other industries that intensively demand the input or occupation are operating intensively in the city (using RCA). If a sufficiently large number (for this purposes of this research project this was arbitrarily set at 10 or more) of industries meets this criterion, the methodology assumes that the input or occupation is available, either directly or indirectly. To study intermediate inputs, the methodology supplements the above method with a "direct" type. In this complementary approach, every input is an industry in itself; therefore, the intensity at which the input industry operates in the city can be directly evaluated. If the input industry displays an RCA equal to or greater than 1, then the input that it offers is also understood to be available. In this way, the methodology assumes that an input or occupation is available in Buenos Aires if a sufficiently large number of industries demanding it intensively are operating intensively in the city or if, in the case of an input, the industry offering it displays a relatively high intensity. 
This exercise produces a list of intermediate inputs and occupations that each diversification opportunity intensively requires, which can be classified as available or lacking/missing. Thus, performance in the "ability to access intermediate inputs" and "ability to access the occupational vector" factors is measured by the total number of inputs and occupations, respectively, that the industry in question intensively requires and is deemed lacking or inaccessible in the city.

The reason why it uses the total number of missing inputs or occupations, rather than the share of missing inputs or occupations over the universe of required inputs or occupations, is because it assumes that acquiring any additional individual input or occupation is equally difficult and that all missing inputs or occupations are required. Hence, this approach seeks to approximate the aggregate total effort to make a diversification opportunity viable. The difficulty in acquiring additional inputs or occupations, and their relative importance can be better approximated through subsequent qualitative exercises.

This information can be used within the framework of a dialog with the private sector. For example, in order to promote investment, authorities could link potential investors in an industry that intensively requires a certain input or occupation with local actors involved in other industries that also demand it intensively. In this way, local actors could share their experience with potential investors regarding how they have been able to meet their needs. Also, if public inputs (for example, ports, airports, electricity, water, etc.) are involved, a means of coordinating with potential investors could be set up to determine their specific needs and jointly agree on a plan of action to ensure their supply. Finally, if private inputs are required, this coordination mechanism could be used to identify the constraints that could impede access to them (for example, regulations, logistical challenges, etc.), in either the local or international market. 


\section{Performance in Viability and Attractiveness Factors (Example)}

Figure 21: Performance in viability factors, TV production and other postproduction services

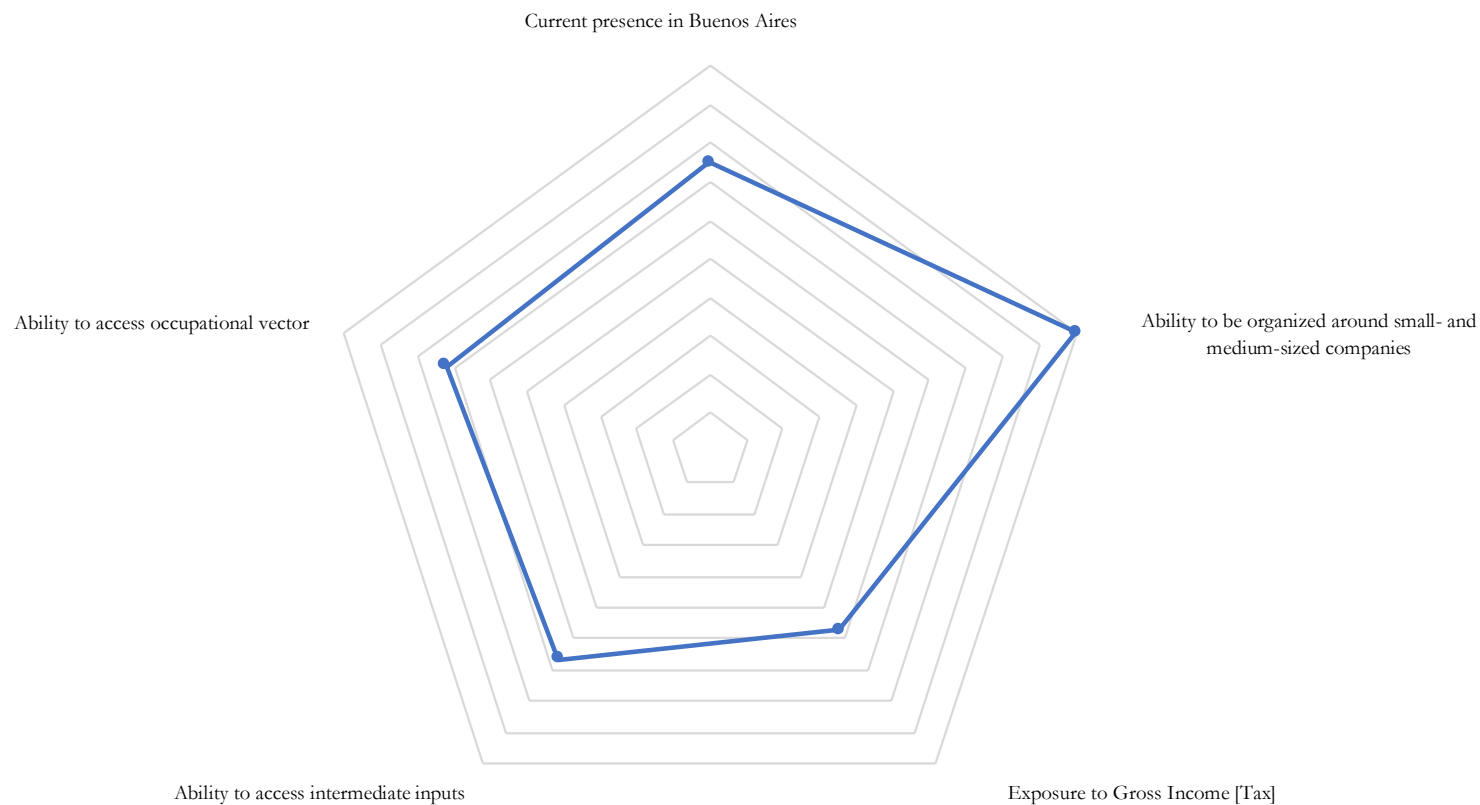

Source: Authors' calculations. 
Figure 22: Performance in attractiveness factors, TV production and other postproduction services

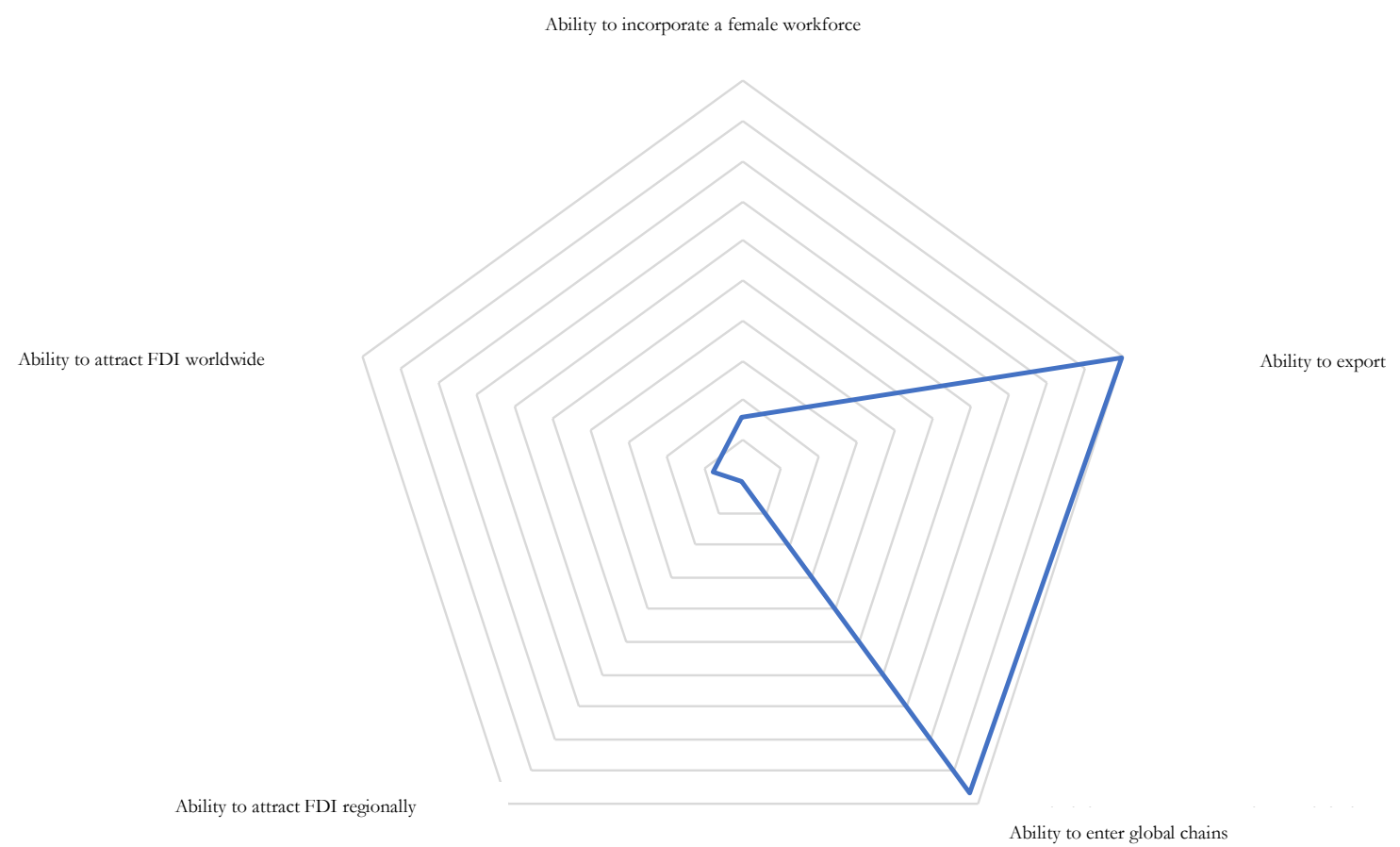

Source: Authors' calculations. 


\section{ANNEX II: Methodological Framework}

We employ two methodological approaches to both analyze the economic performance of Buenos Aires and identify relevant inputs for designing productive policies: growth diagnostic and economic complexity analysis.

\section{Growth Diagnostic}

The growth diagnostic methodology, introduced by Hausmann, Rodrik, and Velasco (2008), seeks to identify the greatest constraints on economic growth that a location faces so that reforms can be targeted on areas where they will have the greatest impact. Generally speaking, this approach is based on three key premises:

- Economic growth is key: Improving living standards must be the main objective of economic and social reforms. Given this objective, economic growth plays an essential part. Therefore, reforms must aim to overcome the constraints holding it back.

- Prioritization: A long list of structural reforms is of little use to governments, especially in view of the administrative, political, and budgetary constraints they face. The methodology indicates the most essential aspects to be resolved.

- Responses to local issues: Reforms based on universal formulas that do not take local context into consideration are unlikely to succeed. Therefore, the growth diagnostic focuses on the issues and/or opportunities each location presents.

The distinguishing feature of this approach is that it considers the different factors determining growth to be complements rather than substitutes. If they are substitutes, a strategy based on improving whatever possible, whenever possible, to the extent possible, will be effective. If, however, we consider inputs to be complements, reforms within a specific sphere will only have an impact to the extent that that factor is actually the binding constraint.

To determine the most relevant constraints, the methodology includes a comprehensive review of potentially constraining factors, running from the general to the specific. The logic is that overall performance is the result of a production function requiring a series of inputs that complement each other and-therefore-must be present to some extent. In practice, this can be operationalized as a decision tree, as illustrated in Figure 1.

The methodology starts by asking why low levels of investment and growth have been observed. Specifically, are the location's activities not very productive/profitable? Or, on the contrary, are activities profitable, but costly to finance? If the evidence points to the latter, some possible explanations are a low savings rate or an inadequate local financial system. If, however, it points to the former, one must ask whether there are shortcomings in the supply of public goods, such as 
infrastructure or human capital. Or are there issues with appropriating the profits from the activities? If so, are these due to government or market failings?

Figure 1: Growth diagnostic decision tree

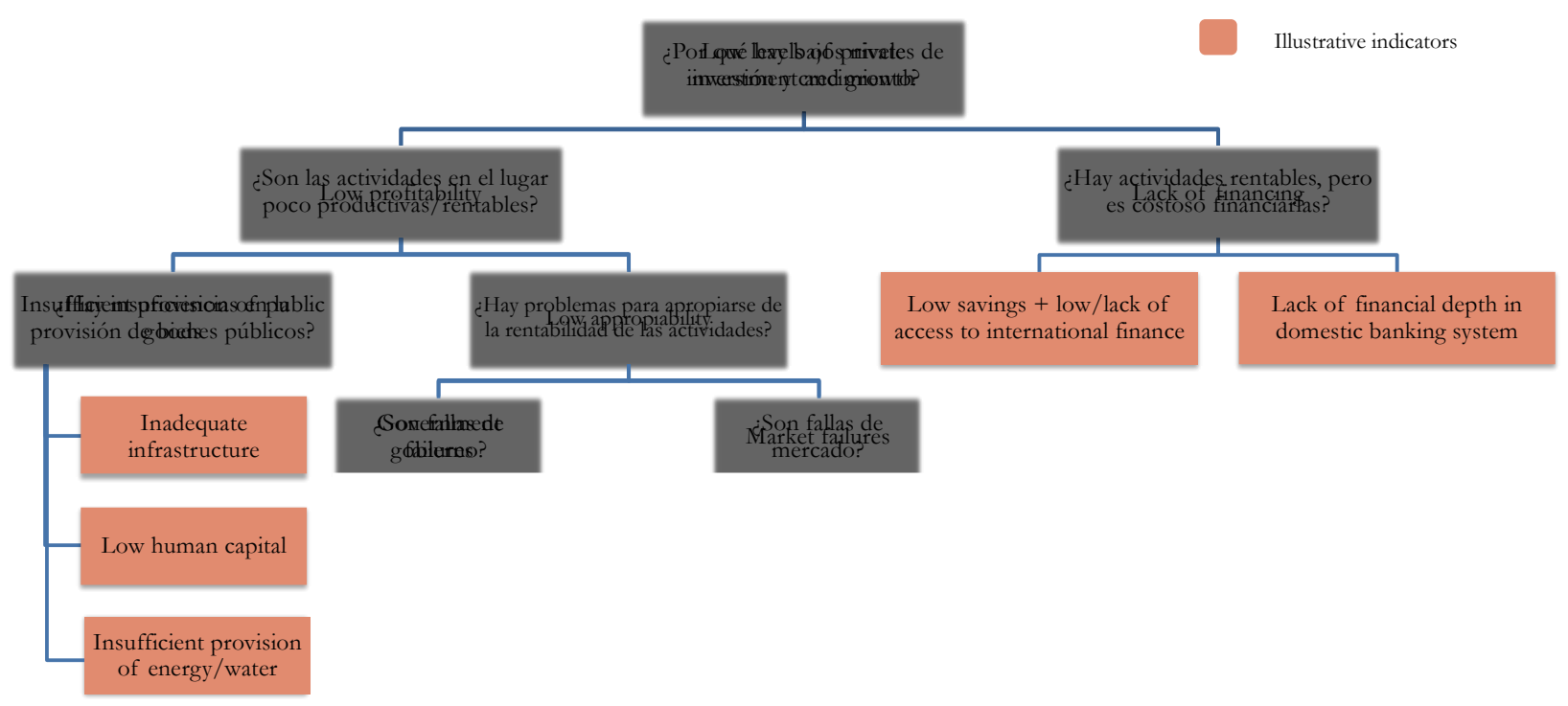

Source: Prepared by the authors based on Hausmann, Rodrik, and Velasco (2008)

To answer the questions posed in the decision tree, the growth diagnostic methodology proposes four principles of differential diagnosis. These principles make it possible to identify whether a factor constitutes a true growth constraint, in which case it must display certain general characteristics:

- The factor's (shadow) price is high: Small quantity is not necessarily a sign that the factor is scarce. The quantity may be small due to scarce supply, in which case the factor would be a constraint, or due to low demand, in which case it would not. The way to differentiate between the two is the price. ${ }^{19}$

- Changes in the factor's availability cause significant changes in performance variables: By definition, if a factor is constraining, changes in its availability should entail changes in the "target function" (e.g., economic growth).

19 In many cases, an input's price is not known or not informative. Under these circumstances, its "shadow price" can be evaluated. (For example, the shadow price of electricity may result from the frequency and duration of power outages or the time and cost required to be connected to the network.) 
- Economic agents attempt to evade the constraint: Economic actors are generally aware of actual constraints blocking their progress, and they probably respond with various efforts to avoid them.

- Agents less intensive in the constraining factor are more likely to succeed: If a factor is constraining in a location, one can expect that those more dependent on that factor will be less successful in that location. Thus, the nature of the sectors in existence and absent in an economy contains valuable information about existing constraints.

Once the principal barriers to growth have been identified, we can focus on political interventions that accelerate growth around the most binding constraints. These interventions may aim to overcome or lessen the constraint directly by dealing with its underlying causes or, alternatively, they may aim to circumvent constraints strategically.

\section{Economic Complexity Analysis}

The economic complexity theory introduced by Hausmann, Hidalgo et al. (2011) is based on the idea that making products requires not only raw materials, labor, and machinery, but also knowledge. According to these authors, a society's potential for growth depends not on what each person knows individually, but on the diversity of knowledge dispersed among different individuals as well as the economy's ability to combine and use this knowledge through interaction networks.

Some economic activities require a wide range of knowledge and are the result of complicated interaction networks. In contrast, other, less sophisticated activities require simpler knowledge. Moreover, locations have varying knowledge bases in terms of quantity and quality. Ultimately, locations develop the products they can, based on their accumulation of knowledge. In other words, locations that make a specific product or provide a specific service show that they have the productive know-how required to develop it.

From this, we can make inferences, making it possible to create economic complexity measurements for locations (Economic Complexity Index, ECI) and products (Industry or Product Complexity Index, PCI). In particular, we find that, on average, locations that have a greater buildup of knowledge tend to be wealthier and are able to produce a more varied and sophisticated set of products that, on average, very few other locations are able to produce. Conversely, locations with less buildup of knowledge tend to be poorer and know how to make very few things that, on average, many other locations are able to make.

Thus, diversity and ubiquity are approximations of the variety of knowledge available at a location and knowledge required to make a product, respectively. In simple terms, locations present greater complexity if they are able to produce a greater variety of products (display high diversity), while products are more complex if they can only be produced by a few locations (display low ubiquity). 
Since economic complexity reflects the level of knowledge embedded in an economy's productive structure, it is not surprising to find a strong positive correlation between complexity measures and income. Furthermore, Hausmann, Hidalgo et al. (2011) found that locations having greater economic complexity than one would expect given their level of income tend to grow more quickly. Thus, economic complexity is not just a symptom or expression of prosperity: it is an engine for growth. Therefore, economic complexity is a relevant concept because it helps explain differences in locations' levels of income and, more importantly, predict future economic growth.

Accordingly, the road to economic development means that locations transition from a simple productive matrix to a more sophisticated one. Hausmann and Klinger (2006) argue that producing new things is very different from producing more of the same thing. Specifically, they assert that the goods and knowledge required to produce a good or service are imperfect substitutes for those required to produce another good or service, and that the degree of substitution varies. Consequently, the probability of a location developing the ability to produce a good or service is related to its installed capacity in producing other, similar goods or services.

Hausmann, Hidalgo et al. (2011) also assert that new capacities will accrue more easily if they are combined with other, existing capacities since this reduces the need to coordinate the simultaneous accrual of numerous new capacities in order to produce a new product. One implication of this assertion is that locations will become diversified, moving from the products and services they already produce to others requiring a similar set of inputs, capabilities, and knowledge. This is to say that the diversification process is "path dependent."

Based on this idea, Hausmann and Klinger (2006) propose a measure of similarity (proximity) among products. In essence, they measure the distance between each product pair using the probability that countries export both. The compilation of all proximities constitutes a network connecting product pairs that are highly likely to be co-exported by many countries, known as the Product Space (goods only) or Industry Space (goods and services).

The placement of a location in this space captures information, both about its productive knowhow and its capacity to expand that knowledge, moving to other nearby products. Based on this data, we can identify opportunities for productive diversification in terms of their probability of success (estimated in terms of the quantity of knowledge that these industries share with those already existing intensively at the location) and impact on current or prospective economic complexity.

It is important to note that the described complexity metrics (ECI, PCI, proximity) have traditionally been calculated using international trade data. Given the lack of data about exports of services having sufficient industrial disaggregation internationally, these metrics are solely focused on goods and have excluded the service sector. However, in view of their relevance for different locations (including Buenos Aires), we have developed certain adjustments to the methodology to include the service sector. To this end, we used the Dun \& Bradstreet (D\&B) database, which contains 
representative employment information having a wide international scope and high degree of industrial disaggregation, for both goods and services.

The adjusted methodology estimates the productive capabilities of the locations according to their relative employment intensity. More specifically, it is based on the concept of Revealed Comparative Advantage (RCA), which is calculated as the proportion of employment in an industry at the location (city) and employment in that same industry worldwide. If this ratio is greater than 1 , one can say that the location has an RCA in the industry, which is the same as saying that it conducts it more intensely than the others.

In turn, the calculation of metrics for industries (PCI and proximity) is based on data for US cities, since the United States is the country most covered by D\&B and is on the technological leading edge. The PCI, as in the original methodology, is estimated according to its ubiquity and the diversity of locations that are intensive in them but using employment instead of exports. Thus, complex industries are those in which only a few highly diversified cities show high relative intensity in employment $(\mathrm{RCA} \geq 1) .^{20}$

Moreover, the proximity between industry peers is calculated using the probability of co-production based on patterns observed in US cities. The logic behind this type of calculation is that two industries probably require similar capabilities and, therefore, are near each other if they are conducted in the same geographic area (city in this case) with relatively high frequency.

${ }^{20}$ A more detailed explanation for how to calculate the product (industry) complexity index can be found in Hausmann, Hidalgo et al. (2011), Technical Text Box 2.1. 